\title{
Polymorphic Nucleic Acid Binding of Bioactive Isoquinoline Alkaloids and Their Role in Cancer
}

\author{
Motilal Maiti and Gopinatha Suresh Kumar \\ Biophysical Chemistry Laboratory, Indian Institute of Chemical Biology (CSIR), Kolkata 700032, India \\ Correspondence should be addressed to Motilal Maiti, mmaiti@iicb.res.in
}

Received 25 June 2009; Revised 11 September 2009; Accepted 14 September 2009

Academic Editor: Hiroshi Sugiyama

Copyright ( $) 2010$ M. Maiti and G. S. Kumar. This is an open access article distributed under the Creative Commons Attribution License, which permits unrestricted use, distribution, and reproduction in any medium, provided the original work is properly cited.

\begin{abstract}
Bioactive alkaloids occupy an important position in applied chemistry and play an indispensable role in medicinal chemistry. Amongst them, isoquinoline alkaloids like berberine, palmatine and coralyne of protoberberine group, sanguinarine of the benzophenanthridine group, and their derivatives represent an important class of molecules for their broad range of clinical and pharmacological utility. In view of their extensive occurrence in various plant species and significantly low toxicities, prospective development and use of these alkaloids as effective anticancer agents are matters of great current interest. This review has focused on the interaction of these alkaloids with polymorphic nucleic acid structures (B-form, A-form, Z-form, $\mathrm{H}^{\mathrm{L}}$-form, triple helical form, quadruplex form) and their topoisomerase inhibitory activity reported by several research groups using various biophysical techniques like spectrophotometry, spectrofluorimetry, thermal melting, circular dichroism, NMR spectroscopy, electrospray ionization mass spectroscopy, viscosity, isothermal titration calorimetry, differential scanning calorimetry, molecular modeling studies, and so forth, to elucidate their mode and mechanism of action for structure-activity relationships. The DNA binding of the planar sanguinarine and coralyne are found to be stronger and thermodynamically more favoured compared to the buckled structure of berberine and palmatine and correlate well with the intercalative mechanism of sanguinarine and coralyne and the partial intercalation by berberine and palmatine. Nucleic acid binding properties are also interpreted in relation to their anticancer activity.
\end{abstract}

\section{Introduction}

The mode of action of many drugs in clinical use for the treatment of cancer, genetic disorders, and viral diseases is believed to be based on their binding to nucleic acids and subsequent modification of the genetic material $[1,2]$. The discovery of the double helical structure of deoxyribonucleic acid (DNA) by Watson and Crick in 1953 [3] and the subsequent revelations relating to the structural features to the basic functional properties of DNA such as replication and transcription have proven the utility of DNA as a potential target for the development of biologically active agents $[4,5]$. Ribonucleic acid (RNA) also play essential role in normal biological process as well as in the progression of many diseases that led to growing interests in exploiting in designing of new class of therapeutics [6-8]. A number of small organic molecules are endowed with cytotoxic properties that are exerted through highly specific but noncovalent and reversible interactions with nucleic acid structures [9-13]. The noncovalent interactions are further classified in terms of intercalation and groove binding. Intercalation occurs when planar aromatic molecules are sandwiched between two adjacent base pairs of nucleic acids. Nonintercalative binding occurs in the major or minor grooves of nucleic acids without inserting any part of the binding molecule between base pairs. The physical and molecular basis of binding of natural alkaloids to nucleic acids has been a subject of extensive study in the recent past [14-17]. Elucidation of the nature, strength and energetics of these interactions may reveal the molecular basis of many antitumor and antiviral natural products and provide helpful guidance for rational drug design of new potential chemotherapeutic agents. The intercalating ligands constitute one of the most widely studied groups as 
<smiles>COc1ccc2cc3[n+](cc2c1OC)CCc1cc2c(cc1-3)OCO2</smiles>

Berberine

(a)<smiles>COc1cc2c(cc1OC)-c1cc3cc(OC)c(OC)cc3c(C)[n+]1CC2</smiles>

Coralyne

(c)<smiles>COc1cc2c(cc1OC)-c1cc3ccc(OC)c(OC)c3c[n+]1CC2</smiles>

(b)<smiles>C[n+]1cc2c3c(ccc2c2ccc4cc5c(cc4c21)OCO5)OCO3</smiles>

Sanguinarine

(d)

Figure 1: Chemical structures of isoquinoline alkaloids.

they form important class of compounds for cancer therapy [18]. In this context, considerable attention has been paid to naturally occurring protoberberine and benzophenanthridine alkaloids for their low toxicity and wide range of biological activities that include antimicrobial, antileukemic, anticancer, and topoisomerase inhibitory activities [19-26]. This review focuses on the complex formation of two groups of isoquinoline alkaloids with various polymorphic nucleic acid structures in relation to their anticancer activities. These alkaloids (Figure 1) include berberine, palmatine, and coralyne of the protoberberine group, sanguinarine of the benzophenanthridine group, and some of their derivatives.

\section{Nucleic Acid Binding Aspects of Bioactive Isoquinoline Alkaloids}

It is generally recognized that the most sensitive target for the inhibition of rapidly proliferating cancer cells are those molecules involved in aspects of DNA function, especially DNA itself. It is, therefore, not surprising that most clinically useful anticancer compounds act against such targets. In this context, significant attention has been focused on the DNA binding properties of protoberberine group of alkaloids that constitute an important class of isoquinoline alkaloids widely present as active constituents of folk medicines used world over for centuries. Several protoberberine alkaloids and their derivatives have been investigated as potential antitumor agents, among which berberine, palmatine, and coralyne (a synthetic analogue of berberine) represent the most intensively studied molecules. The physicochemical properties of protoberberine alkaloids presented in Table 1 provide an understanding of the similarity and differences in their chemical structures (Figure 1) and properties. The basic skeleton of the quaternary protoberberine moiety is 5,6-dihydro[a,g] quinolizinium [29]. In berberine, there is an addition of 2,3methylenedioxy and 9,10 dimethoxy group to the above basic structure and thus the structure of berberine becomes 7,8,13,13a-tetrahydro-9,10-dimethoxy and 2,3 methylenedioxy berberinium. On the other hand, palmatine has the same tetracyclic structure $(7,8,13,13 a$-tetradehydro- 9,10 dimethoxy-2,3, methylene dioxy berberinium) as berberine but differs by the nature of the substituents at position 2,3 on the benzo ring; being dimethoxy for palmatine. Similarly coralyne has the basic structure with a methyl group attached to the $\mathrm{C} 8$ position. Notably, while berberine and palmatine have buckled structures, coralyne has a planar structure. In aqueous condition, the absorption spectra of berberine and palmatine are similar while that of coralyne is remarkably different. Both berberine and palmatine have weak intrinsic fluorescence emission spectra while coralyne has a strong fluorescence emission spectrum in aqueous and alcoholic media. Berberine, palmatine, and coralyne are achiral molecules as evidenced from circular dichroism spectroscopy. Sanguinarine is the most important member of 
TABLE 1: Some physicochemical properties of isoquinoline alkaloids $[15,16,27,28]$.

\begin{tabular}{|c|c|c|c|c|}
\hline Properties & Berberine & Palmatine & Coralyne & $\begin{array}{l}\text { Sanguinarine } \\
\text { (iminium form) }\end{array}$ \\
\hline Empirical formulae & $\mathrm{C}_{20} \mathrm{H}_{18} \mathrm{O}_{4} \mathrm{~N}^{+}$ & $\mathrm{C}_{21} \mathrm{H}_{22} \mathrm{O}_{4} \mathrm{~N}^{+}$ & $\mathrm{C}_{22} \mathrm{H}_{22} \mathrm{O}_{4} \mathrm{~N}^{+}$ & \\
\hline Chemical name & $\begin{array}{l}\text { 7,8,13,13a-tetradehydro- } \\
\text { 9,10-dimethoxy-2,3- } \\
\text { methylenedioxy } \\
\text { berberinium }\end{array}$ & $\begin{array}{l}7,8,13,13 a- \\
\text { tetradehydro- } \\
2,3,9,10- \\
\text { tetramethoxy- } \\
\text { berberinium }\end{array}$ & $\begin{array}{l}5,6,7,8,13,13 \mathrm{a}- \\
\text { hexadehydro- } 8 \text {-methyl- } \\
\text { 2,3,10,11-tetramethoxy } \\
\text { berberinium }\end{array}$ & $\begin{array}{l}\mathrm{C}_{20} \mathrm{H}_{14} \mathrm{O}_{4} \mathrm{~N}^{+}(13- \\
\text { methyl } \\
{[1,3] \text { benzodioxolo }} \\
{[5,6-\mathrm{c}]-1,3-} \\
\text { dioxolo[4,5-i]- } \\
\text { phenanthridium }\left(1^{+}\right)\end{array}$ \\
\hline Crystal colour & Yellow & Canary yellow & Dark yellow & $\begin{array}{l}\text { Chloride salts are } \\
\text { orange red }\end{array}$ \\
\hline Solubility & Water & Water & Ethanol & $\begin{array}{l}\text { Salts are soluble in } \\
\text { water }\end{array}$ \\
\hline Molecular weight (ion) & 336.36 & 352.50 & 364.42 & 332.33 \\
\hline Melting point $\left({ }^{\circ} \mathrm{C}\right)$ & 210 (chloride salt) & 221 (chloride salt) & 250-252 (chloride salt) & $277-280^{\circ} \mathrm{C}$ \\
\hline $\begin{array}{l}\text { Peak position of absorption } \\
\text { spectrum }(\mathrm{nm})\end{array}$ & $\begin{array}{l}\text { 230, 267, } 344 \text { and } 420 \\
\text { (in aqueous buffer) }\end{array}$ & $\begin{array}{l}232,268,344.5 \text { and } \\
420 \text { (in aqueous } \\
\text { buffer) }\end{array}$ & $\begin{array}{l}219,231,300,311326, \\
360,405 \text {, and } 424 \text { (in } 30 \% \\
\text { ethanol) } 219,231,300,311 \\
326,360,405 \text {, and } 420 \text { (in } \\
\text { aqueous buffer) }\end{array}$ & $\begin{array}{l}273,327,400 \text { and } \\
475 \mathrm{~nm} \text { (in aqueous } \\
\text { buffer of } \mathrm{pH} 5.5 \text { ) }\end{array}$ \\
\hline $\begin{array}{l}\text { Molar extinction coefficient } \\
(\varepsilon)\left(\mathrm{M}^{-1} \mathrm{~cm}^{-1}\right)\end{array}$ & 22,500 at $344 \mathrm{~nm}$ & 25,000 at $344 \mathrm{~nm}$ & $\begin{array}{l}14,500 \text { at } 420 \mathrm{~nm} \text { (in } \\
\text { aqueous buffer) and } \\
17,500 \text { at } 424 \mathrm{~nm}(30 \% \\
\text { alcohol) }\end{array}$ & $\begin{array}{l}30,700 \mathrm{M}^{-1} \mathrm{~cm}^{-1} \text { at } \\
327 \mathrm{~nm} \text { in } 0.1 \mathrm{~N} \mathrm{HCl}\end{array}$ \\
\hline $\begin{array}{l}\text { Peak position of fluorescence } \\
\text { emission spectrum }\end{array}$ & $\begin{array}{l}\text { Very weak, at } 530 \mathrm{~nm} \\
\left(\lambda_{\text {ex }} 350 \mathrm{~nm}\right)\end{array}$ & $\begin{array}{l}\text { Very weak, at } 530 \mathrm{~nm} \\
\left(\lambda_{\text {ex }} 350 \mathrm{~nm}\right)\end{array}$ & $\begin{array}{l}\text { Strong, at } 470 \mathrm{~nm} \text { (both in } \\
\text { aqueous and alcoholic } \\
\text { media) }\left(\lambda_{\mathrm{ex}} \text { at } 424 \mathrm{~nm}\right)\end{array}$ & $\begin{array}{l}\text { at } 580 \mathrm{~nm}\left(\lambda_{\mathrm{ex}} 327\right. \\
\text { or } 475 \mathrm{~nm})\end{array}$ \\
\hline Optical rotation $[\alpha]_{\mathrm{D}}$ (solvent) & $0^{\circ}\left(\mathrm{H}_{2} \mathrm{O}\right)$ & $0^{\circ}\left(\mathrm{H}_{2} \mathrm{O}\right)$ & $\begin{array}{l}0^{\circ} \text { (in } \mathrm{H}_{2} \mathrm{O} \text { and } 30 \% \\
\text { ethanol) }\end{array}$ & $0^{\circ}$ (zero degree $)$ \\
\hline $\mathrm{IC}_{50}$ value (in mice) & $27.5 \mathrm{mg} / \mathrm{Kg}$ & $65 \mathrm{mg} / \mathrm{Kg}$ & $40 \mathrm{mg} / \mathrm{Kg}$ & $19.4 \mathrm{mg} / \mathrm{Kg}$ \\
\hline
\end{tabular}

the benzophenanthridine group. It exhibited $\mathrm{pH}$ dependent structural equilibrium between the iminium (charged) and the alkanolamine (neutral) forms with a pKa value of 7.4 [15]. Sanguinarine existed almost exclusively as iminium and alkanolamine forms in the $\mathrm{pH}$ rang $1.0-6.0$ and 8.511.0 , respectively. The characteristic uv-vis absorption and fluorescence spectra of each form were studied [15]. One interesting point to be noted is that the fluorescence of alkanolamine form is more intense than that of iminium form. The iminium form is unsaturated and completely planar while alkanolamine form has buckled structure. Both forms are achiral. Some physicochemical properties of sanguinarine are given in Table 1.

2.1. Alkaloid-DNA Interaction. The most convenient tool for detecting the complex formation between nucleic acids and small molecules is absorbance spectra. Like many other small molecules that bind nucleic acids, berberine has by virtue of heterocyclic structure visible absorption band where DNA does not contribute and hence is convenient to monitor the binding. The complex formation essentially involves bathochromic and hypochromic effect on its absorption spectrum with clear isosbestic points indicating the onset of equilibrium binding. The bathochromic shift of the spectrum of the free alkaloid on interaction with DNA indicates the binding of individual alkaloid to DNA substrate, that is, no aggregation prevails [35]. Moreover, such red shift presumably arises from the strong intermolecular interaction involving the effective overlapping of the electronic cloud of the base pairs of DNA with that of the alkaloid. Again, the less polar environment of the bound ligand can cause the hypochromic effect on the free absorption spectrum of the ligand and intercalative positions are hydrophobic in nature.

A large number of studies reported the complexation of berberine with calf thymus DNA possibly by a mechanism of partial intercalation $[15,16]$ and references therein. Maiti et al. [30, 36-38] have first demonstrated the base and sequence specificity of berberine from studies with several naturally occurring and synthetic DNAs of differing base composition and sequences as evidenced from hypochromism and bathochromism in the absorption spectrum (Figure 2), remarkable enhancement of steady-state fluorescence emission intensity, stabilization of DNA against thermal denaturation, and perturbation in the circular dichroism spectrum. Berberine increased the contour length of sonicated rod like duplex B-DNA depending on base composition and induced the unwinding-rewinding process of covalently closed superhelical DNA with an unwinding angle of $13^{\circ}$. Using high-field NMR, Saran et al. [39] first proposed that berberine binds to double helical calf thymus 


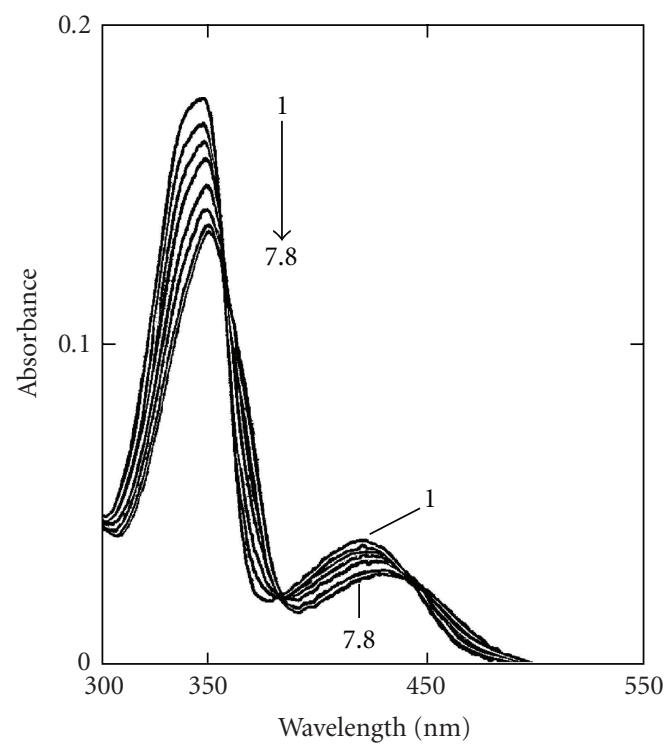

Figure 2: Absorption spectrum (1) of berberine $(8 \mu \mathrm{M})$ with increasing concentration up to $117.6 \mu \mathrm{M}$ (7) and $125.0 \mu \mathrm{M}$ (8) of calf thymus DNA. Reprinted from the Ph.D. Thesis of Bhadra [28].

DNA by a mechanism of partial intercalation in which the planar isoquinoline moiety remained intercalated between base pairs. The partial intercalation model was further substantiated from several analytical techniques that included absorption, fluorescence, isothermal titration calorimetry, differential scanning calorimetry, electrospray ionization mass spectroscopy, in combination with computer molecular modeling studies [27, 40-43]. However, a fluorescence spectral study of berberine with calf thymus DNA [44] and a high-resolution ${ }^{1} \mathrm{HNMR}$ and UV spectroscopy [45] in conjunction with molecular modeling studies on berberine binding to various short oligonucleotide duplexes (B-form) favoured a groove binding geometry. This suggested that berberine is located in the minor groove with a preference for AT sequences, lying with the convex side on the helix groove where the positively charged nitrogen atom is close to the negative ionic surface of the oligonucleotide helices. Zhu et al. [46] supported the interaction of berberine with B-DNA by partial intercalation in which isoquinoline part intercalated in presence of $\beta$-cyclodextrin. However, Chen et al. [47] studied the interaction of berberine with several double stranded oligonucleotides [d(AAGAATTCTT)2, d(AAGGATCCTT)2, and d(AAGCATGCTT)2 using electrospray ionization mass (ESI-MS) and fluorescence spectroscopic techniques to establish the sequence selectivity and preference of binding to these structures. The results from ESI-MS and fluorescence titration experiments indicated that the sequence selectivity of berberine was not significant and remarkable AT rich DNA binding preference was not observed.

It is known that alternating GC polymer and its methylated analogue structures assumes left-handed conformation (Z-DNA) in high molar salt $\left(\mathrm{Na}^{+}, \mathrm{K}^{+}\right)$, in low molar divalent cations $\left(\mathrm{Ca}^{2+}, \mathrm{Mg}^{2+}, \mathrm{Ni}^{2+}\right)$, micromolar concentration of hexamine cobalt chloride, and millimolar concentration of polyamines. In order to analyze the binding of berberine to Z-form DNA, Kumar et al. [49] reported that Z-DNA structure remained invariant in the presence of berberine up to a nucleotide phosphate /alkaloid molar ratio of $\sim 0.8$ and suggested that berberine neither bound to Z-form DNA nor converted the Z-DNA to the bound B-form structure like other intercalators [15].

The molecular architecture of the $\mathrm{H}^{\mathrm{L}}$-from DNA appears to be unique, stable left-handed structure with Hoogsteen base pairs, is distinctly different from the right-handed BDNA and left-handed Z-DNA $[15,16]$. The binding of berberine to $\mathrm{H}^{\mathrm{L}}$-DNA was found to be non-cooperative resulting in perturbation of the circular dichroism spectrum and generation of extrinsic circular dichroism bands with opposite sign and magnitude compared to the B-form DNA [49]. It was suggested that berberine could be used as a probe to detect the alternation of structural handedness due to protonation and may potentiate its use in regulatory roles for biological functions.

The formation of intermolecular triplex offers a means of achieving sequence specific recognition of duplex DNA forming specific hydrogen bonds. Although the third strand oligonucleotide possesses specific sequence recognition properties, the binding is not so strong which results in a relatively low stability of the triplex structure. The instability of triple helical structures under normal physiological conditions is a critical limitation that restricts their uses in vivo. Several intercalating ligands have now been reported that can preferentially stabilize triplex structures [50-55]. Ren and Chaires [50] have shown that berberine preferentially and very strongly bound to TxA.T triplex compared to AT duplex using novel competition dialysis and thermal melting experiments. Recently Das et al. [48] demonstrated that berberine stabilized the Hoogsteen basepaired third strand of TxA.T triplex without affecting the Watson-Crick strands as revealed from thermal melting (Figure 3(a)) and circular dichroic studies (Figure 3(b)) and proposed that it binds to the third strand presumably by mechanism of intercalation. Thermodynamics of berberinetriplex complexation revealed that the binding process was exothermic and entropy driven favouring a tight binding at the intercalation site [48].

In recent years, recognition that certain sequences promote formation of higher-order structures of DNA has revealed new targets for chemotherapy [58-60]. These structures can form the association of four single strands containing tracts of guanine bases (tetramer), and can also arise within one or two strands containing several of these sequences as the strands fold back upon themselves. In order to understand the potential of quadruplex DNA as a chemotherapeutic target, it is important to understand the role and occurrence of telomeres in cells. Guanine rich sequences with the ability to form quadruplex structures are found in telomeres at the end of eukaryotic chromosomes (TTAGGG repeats in humans) as well as in promoter regions of genes and in recombination sites [61,62]. Telomeres are pieces of DNA that are extensions of linear chromosomes [63]. The observations that telomerase is expressed in 


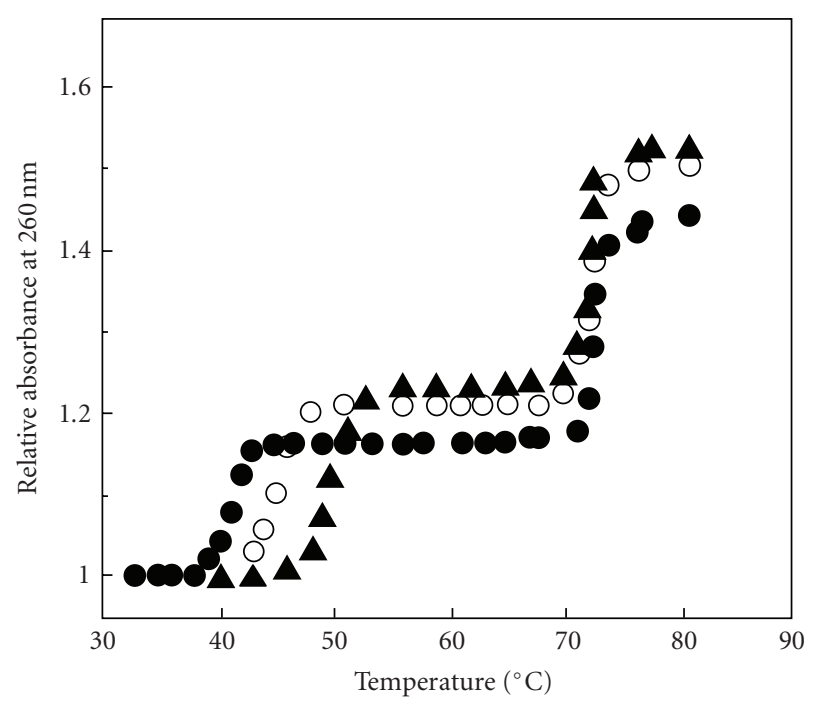

(a)

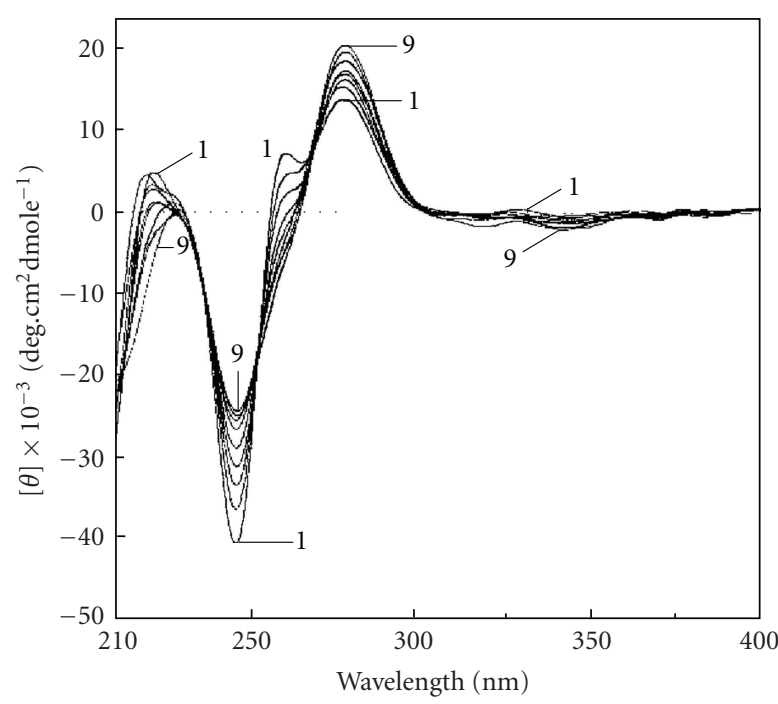

(b)

FIGURE 3: (a) The thermal melting profile of poly $(\mathrm{dT}) \cdot \operatorname{poly}(\mathrm{dA}) \operatorname{xpoly}(\mathrm{dT})$ triplex $(-\bullet-)$ and its complex with berberine at alkaloid/DNA ratio of $0.1\left(-\mathrm{O}_{-}\right)$and $0.3(-\mathbf{\Delta -})$. (b) Circular dichroic spectrum (1) of the same triplex $(48.8 \mu \mathrm{M})$ with increasing concentrations up to $(31.05 \mu \mathrm{M})$ of berberine (9). Reprinted in part from Das et al. [48] with permission from 2003 Adenine Press.

TABLE 2: Comparative binding parameters of interaction of various alkaloids with calf thymus DNA and covalently closed superhelical DNA.

\begin{tabular}{|c|c|c|c|c|c|c|}
\hline Alkaloid & $K^{\mathrm{a}}\left(\times 10^{5} \mathrm{M}^{-1}\right)$ & $n$ & $\Delta T_{m}{ }^{\mathrm{b}}\left({ }^{\circ} \mathrm{C}\right)$ & $\beta^{c}$ & $\theta^{\mathrm{d}}$ & References \\
\hline \multirow{2}{*}{ Berberine } & \multirow{2}{*}{0.38} & \multirow{2}{*}{4.0} & \multirow{2}{*}{7.0} & \multirow{2}{*}{1.35} & 12.6 & \multirow{2}{*}[28,30]{} \\
\hline & & & & & 13.0 & \\
\hline Palmatine & 0.19 & 4.0 & 11.0 & 1.40 & 15.0 & {$[28,31]$} \\
\hline \multirow[t]{2}{*}{ Coralyne } & \multirow[t]{2}{*}{1.0} & \multirow[t]{2}{*}{9.0} & \multirow[t]{2}{*}{12.0} & \multirow[t]{2}{*}{1.62} & 21.0 & \multirow[t]{2}{*}[28,32]{} \\
\hline & & & & & 18.0 & \\
\hline Sanguinarine & 9.45 & 3.4 & 21.3 & 1.86 & 27.0 & {$[33,34]$} \\
\hline
\end{tabular}

${ }^{a} K$ the intrinsic binding constant determined using equation $r / C_{\mathrm{f}}=K(1-n r)[(1-n r) /(1-(n-1) r)]^{n-1}$, where $r$ is the number of alkaloid molecules bound per mole of nucleotide and $C_{\mathrm{f}}$ is the molar concentration of free alkaloid, where $n$ denotes the binding site size in base pairs.

${ }^{\mathrm{b}} \Delta T_{m}$ is the $T_{m}$ of the DNA in the presence of alkaloid- $T_{m}$ of the free DNA.

${ }^{c} \beta$ value was calculated from the slope, when $L / L_{o}$ or $\left(\eta / \eta_{0}\right)^{1 / 3}$ is plotted against $r$ using the equation $L / L_{o}=\left(\eta / \eta_{0}\right)^{1 / 3}=1+\beta r$, where $L$ and $L_{o}$ are the contour length of helix in presence and absence of ligand corresponding values of intrinsic viscosity (approximated to the reduced viscosity) of the solution and $r$ is the mole ligand bound /mole nucleotides.

$\mathrm{d}$ unwinding angle.

malignant but not normal tissues led to the paradigm that drugs that interfere with the action of telomerase could be expected to cause the death of cancer cells. If interactions of telomeric proteins with specific sequences of telomeric DNA are lost, this also leads to cell death by apoptosis [64]. This suggests that compounds that bind to DNA and inhibit protein binding would cause the rapid death of tumor cells. Compounds that stabilize quadruplex DNA, presumably preventing interactions with proteins have been shown in vitro to inhibit telomerase [65]. Recent studies show that berberine inhibits telomere elongation [66] and binds strongly to various G-quadruplex DNA structures and inhibits telomerase activity [50,67]. Thus berberine may be used as a target to probe for G-quadruplex DNA for its development as potential antitumor drugs.

Palmatine is structurally similar to the well-known isoquinoline alkaloid berberine. To evaluate the affinity and mode of binding to B-DNA, Kluza et al. [69] and
Bhadra et al. [31] reported that addition of calf thymus DNA caused marked changes in the absorption spectrum of palmatine (Figure 4) with strong hypochromic and bathochromic shifts, with well-resolved isosbestic points, and with increased thermal melting temperature to form stable complexes with B-DNA. Further from electric linear dichroism studies, it was interpreted that palmatine binds either by an intercalation or by an external stacking parallel to the base pairs. However, an earlier study by Yu et al. [70] proposed a nonintercalative binding of palmatine. Recently, the author's laboratory [56] demonstrated the base and sequence-dependent binding of palmatine and established that palmatine formed a partial intercalation complex with all the polymers except the homo and heteropolymer of GC, with which it formed a nonintercalative complex. The binding of palmatine to calf thymus DNA was further characterized by thermodynamic studies using isothermal titration calorimetry and the binding process was exothermic 
TABLE 3: Thermodynamic parameters for the interaction of various alkaloids with calf thymus DNA complexation obtained from isothermal titration calorimetric studies ${ }^{\mathrm{a}}$.

\begin{tabular}{lcccccc}
\hline Alkaloid & $K\left(\times 10^{5} \mathrm{M}^{-1}\right)$ & $n$ & $\Delta G^{\circ}\left(\mathrm{kcal} \mathrm{mol}^{-1}\right)$ & $\Delta H^{\circ}\left(\mathrm{kcal} \mathrm{mol}^{-1}\right)$ & $\Delta S^{\circ}\left(\mathrm{cal}^{\circ} \cdot \mathrm{deg}^{-1} \mathrm{~mol}^{-1}\right)$ & References \\
\hline Berberine & 0.12 & 3.6 & -5.50 & -2.01 & +11.40 & +5.00 \\
Palmatine & 0.28 & 3.0 & -5.82 & -4.40 & -7.05 & +7.70 \\
Coralyne & 71.5 & 4.0 & -9.25 & -6.91 & +3.70 & {$[28,56]$} \\
Sanguinarine & 9.52 & 2.2 & -8.02 & {$[28,42]$} \\
\hline
\end{tabular}

${ }^{a}$ Average of four determinations, $K$ and $\Delta H^{\circ}$ values were determined from fits of the ITC profiles to Origin 7.0. The values of $\Delta G^{\circ}$ and $\Delta S^{\circ}$ were determined using the equations $\Delta G^{\circ}=-(R T \ln K)$ and $\Delta G^{\circ}=\Delta H^{\circ}-T \Delta S^{\circ}$. respectively. The ITC profile was fit to a model of single binding sites, where $n$ denotes the binding site size.

TABLE 4: Spectroscopic and thermodynamic parameters for the interaction of various alkaloids with DNA triple helical structure with references ${ }^{\mathrm{a}}$.

\begin{tabular}{|c|c|c|c|c|c|c|c|}
\hline \multirow[t]{2}{*}{ Complexes } & $K^{\mathrm{a}}$ & $n$ & $\Delta T_{m}{ }^{\mathrm{b}}$ & $\Delta G^{\circ}$ & $\Delta H^{\circ}$ & $\Delta S^{\circ}$ & References \\
\hline & $\left(\times 10^{5} \mathrm{M}^{-1}\right)$ & & $\left({ }^{\circ} \mathrm{C}\right)(3 \rightarrow 2)$ at $r_{\max }$ & $\mathrm{kcal} \mathrm{mol}^{-1}$ & $\mathrm{kcal} \mathrm{mol}^{-1}$ & $\mathrm{cal} \cdot \mathrm{deg}^{-1} \mathrm{~mol}^{-1}$ & \\
\hline $\operatorname{Poly}(\mathrm{dT}) \cdot \operatorname{poly}(\mathrm{dA}) \operatorname{xpoly}(\mathrm{dT})+$ berberine & 3.2 & 6.4 & 7.80 & -7.35 & -4.61 & +9.52 & {$[48]$} \\
\hline $\operatorname{Poly}(\mathrm{dT}) \cdot \operatorname{poly}(\mathrm{dA}) \operatorname{xpoly}(\mathrm{dT})+$ coralyne & dna & dna & 19.0 & dna & dna & dna & [68] \\
\hline $\operatorname{Poly}(\mathrm{dT}) \cdot \operatorname{poly}(\mathrm{dA}) \operatorname{xpoly}(\mathrm{dT})+$ sanguinarine & 26.0 & 3.3 & 24.5 & -8.56 & -4.14 & +15.11 & {$[48]$} \\
\hline $\operatorname{Poly}(\mathrm{dC}) \cdot \operatorname{poly}(\mathrm{dG}) \operatorname{xpoly}\left(\mathrm{dC}^{+}\right)+$sanguinarine & 16.0 & 2.5 & 7.50 & -8.28 & -10.73 & -8.36 & {$[48]$} \\
\hline
\end{tabular}

${ }^{\mathrm{a}} K$ (the intrinsic binding constant) determined using equation $r / C_{\mathrm{f}}=K(1-n r)[(1-n r) /(1-(n-1) r)]^{n-1}$, where $r$ is the number of alkaloid molecules bound per mole of nucleotide and $C_{\mathrm{f}}$ is the molar concentration of free alkaloid.

${ }^{\mathrm{b}} \Delta T_{m}(3 \rightarrow 2)$ is the $T_{m}$ of the triplex DNA in the presence of alkaloid- $T_{m}$ of the free triplex DNA. $(3 \rightarrow 2)$ denotes the transition temperature from triplex complex to duplex complex formation.

* dna: data not available.

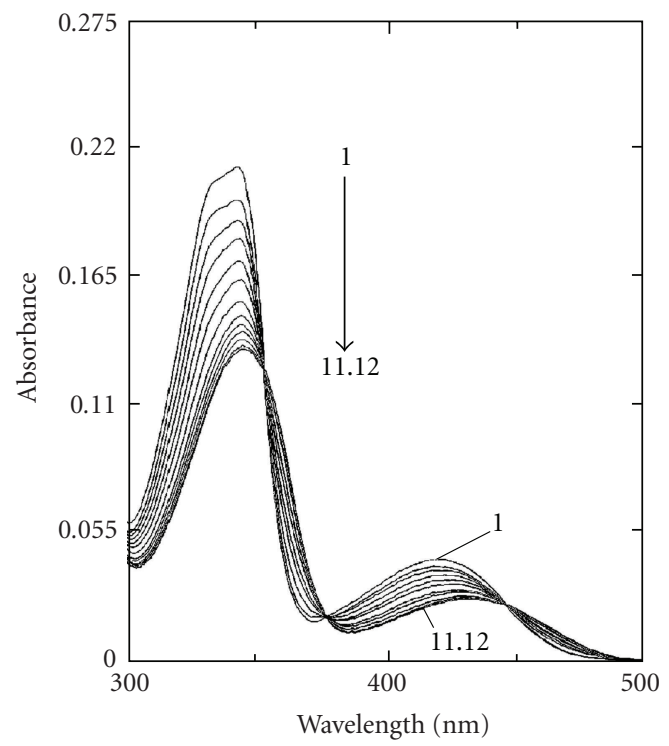

Figure 4: Absorption spectrum (1) of palmatine $(7.6 \mu \mathrm{M})$ with increasing concentrations up to $151.6 \mu \mathrm{M}(11)$ and $175.2 \mu \mathrm{M}(12)$ of calf thymus DNA. Reprinted from the Ph.D. Thesis of Bhadra [28].

and entropy-driven which favour the intercalative mode of binding. It does not bind to Z-DNA nor does it convert Zform to B-form. Unlike berberine, palmatine showed very weak binding to $\mathrm{H}^{\mathrm{L}}$-form. To date there is no report on the binding of palmatine to higher-order DNA structures, triplexes, and quadruplexes and study in this direction is awaited.
Another important alkaloid of protoberberine group is the synthetic molecule coralyne, which was found to be potentially capable of intercalating with B-DNA [32, 73, 74] and the results led to the assumption that the DNA binding may be correlated with biological activity. It was reported that at a lower molar ratio of coralyne to BDNA, an intercalating complex by $\pi$ stacking along the backbone of DNA, while at higher molar ratios, a DNAinduced aggregation occurred [73]. Although a wealth of data $[32,73,74]$ is presently available regarding the complex formation between coralyne and B-DNA, the interpretation of these data needs to be performed with caution as coralyne exhibits a high tendency of aggregation in aqueous buffer even at very low concentrations. Maiti et al. [32] first addressed this problem and showed that aqueous solutions containing $30 \%(\mathrm{v} / \mathrm{v})$ ethanol suppressed the aggregation of coralyne and allowed spectrophotometric titration of a fully monomeric form with calf thymus DNA. The base and sequence specificity of coralyne (monomeric) on binding to various naturally occurring and synthetic B-DNA were studied by spectrophotometric and spectrofluorimetric titrations, circular dichroic spectroscopy, thermal melting, isothermal titration calorimetry, and viscometric studies. The results of spectrophotometric and calorimetric studies of a fully monomeric form of coralyne with calf thymus DNA is presented in Figures 5(a) and 5(b), respectively. Coralyne increased the contour length of sonicated rod like duplex B-DNA and induced the unwinding and rewinding process of covalently closed superhelical B-DNA with an unwinding angle of $21^{\circ}$. These experiments revealed that monomeric coralyne binds to B-DNA by a mechanism of intercalation with a relatively high specificity toward 


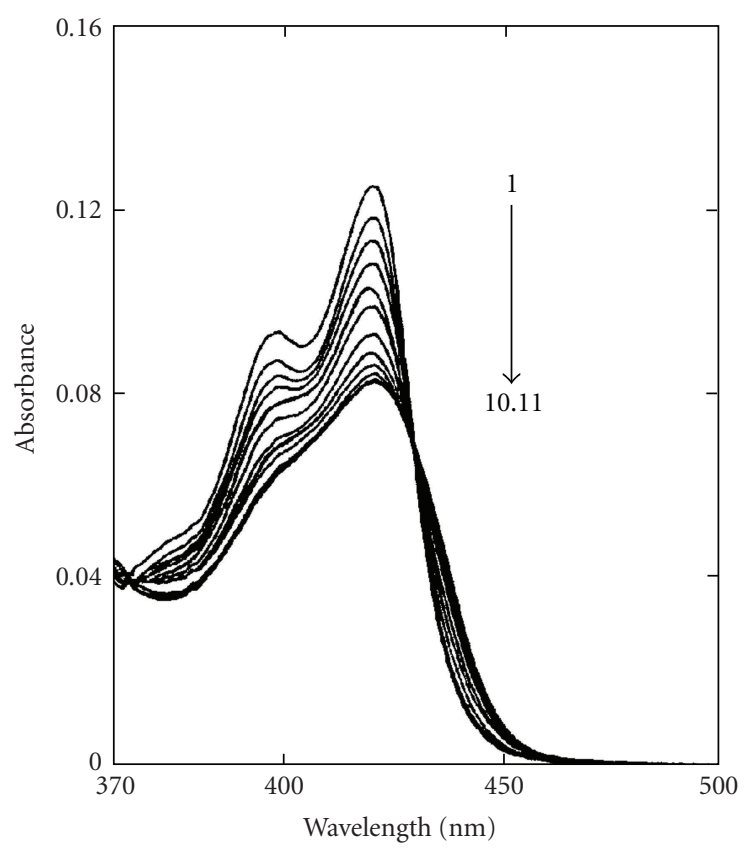

(a)

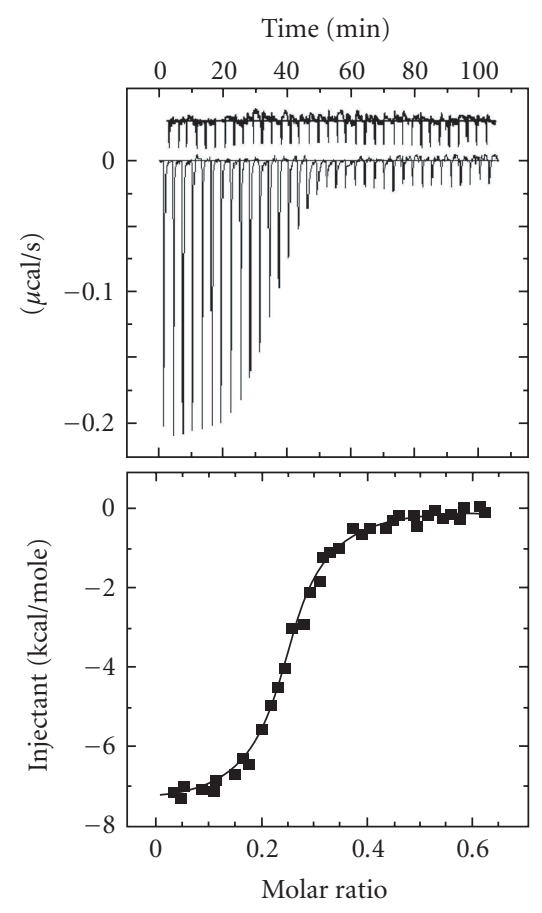

(b)

Figure 5: (a) Absorption spectrum (1) of coralyne (7.09 $\mu \mathrm{M})$ with increasing concentrations up to $81.73 \mu \mathrm{M}(10)$ and $96.28 \mu \mathrm{M}(11)$ of calf thymus DNA. (b) The ITC profiles for the titration of calf thymus DNA $(65 \mu \mathrm{M})$ to coralyne $(15 \mu \mathrm{M})$ at $20^{\circ} \mathrm{C}$. Each heat burst curve in the upper panel is the result of a $5 \mu \mathrm{L}$ injection of DNA into coralyne. The lower panel represents the corresponding normalized heat signals versus molar ratio. The data points reflect the experimental injection and the solid line represents the best fit of the data. Reprinted from the Ph.D. Thesis of Bhadra, [28].

TABLE 5: Effect of berberine incubated with S180 cells in vitro ${ }^{\text {a }}$.

\begin{tabular}{lcc}
\hline Pathway & \multicolumn{2}{c}{ Percent control } \\
\hline Glycine $\rightarrow\left[{ }^{14} \mathrm{C}\right]$ Protein & $4 \mu \mathrm{g} / \mathrm{mL}$ & $40 \mu \mathrm{g} / \mathrm{mL}$ \\
Thymine $\rightarrow\left[{ }^{3} \mathrm{H}\right]$ DNA & 2.9 & 0.1 \\
Uridine $\rightarrow\left[{ }^{3} \mathrm{H}\right]$ RNA & 48.9 & 1.6 \\
\hline
\end{tabular}

${ }^{a}$ Data obtained from W. A. Creasey [80].

alternating GC sequences. Comparative spectroscopic and thermodynamics binding parameters for the interaction of isoquinoline alkaloids with calf thymus DNA are presented in Tables 2 and 3, respectively. Recently, it has been reported $[28,75]$ that coralyne, unlike other classical intercalators, binds to Z- form DNA without converting the bound form to the B-form bound structure as revealed from circular dichroic spectroscopy. Studies indicated that coralyne could be used as a probe to detect the Z-form structure in vivo [28]. Coralyne showed strong perturbation of circular dichroic spectrum of $\mathrm{H}^{\mathrm{L}}$-form DNA (Figure 6). However, the mode and mechanism of binding of coralyne- $\mathrm{H}^{\mathrm{L}}$-DNA complexation could not be revealed from these studies.

In addition, coralyne was shown to bind to parallel triplex DNA but it does not bind to antiparallel triplex DNA [53]. It was concluded from early experiments using thermal denaturation analysis and spectrophotometric titra- tion with TxA.T and CxG.C ${ }^{+}$containing DNA triplexes that coralyne does not exhibit significant sequence selectivity during triplex complexation [68]. A later study, however, using various techniques like DNase foot printing, thermal denaturation analysis, spectrophotometric titration and circular dichroic, as well as NMR spectroscopy, showed a preferential intercalation of coralyne into TxA.T triplexes [81], whereas in $\mathrm{CxG} . \mathrm{C}^{+}$triplexes, the coralyne molecule was only partially intercalated due to the electronic repulsion between the cationic alkaloid and protonated cytosine. The high propensity of coralyne to stabilize triplex DNA has been demonstrated by Hud et al. [55, 82] from the observation that duplex poly $(\mathrm{dT}) \cdot \operatorname{poly}(\mathrm{dA})$ is transformed into a mixture of poly $(\mathrm{dT}) \operatorname{xpoly}(\mathrm{dA}) \cdot \operatorname{poly}(\mathrm{dT})$ triplex and single stranded poly $(\mathrm{dA})$ in presence of coralyne at slightly elevated temperature $\left(T>37^{\circ} \mathrm{C}\right)$. This disproportionation reaction of double-stranded DNA has been rationalized in terms of the formation of a highly stable intercalation complex between coralyne and triplex DNA. Further, they demonstrated that coralyne may act as a template for the formation of an antiparallel DNA triplex from homoadenine sequences [83]. Coralyne was found suitable for stacking interactions with G-quadruplex [67]. In this study it was shown that coralyne has the ability to induce and stabilize various G-quadruplex structures including human G-quadruplex as well as its efficiency in inhibiting telomerase. The thermal stabilization of a preformed intermolecular G-quadruplex structure shows 


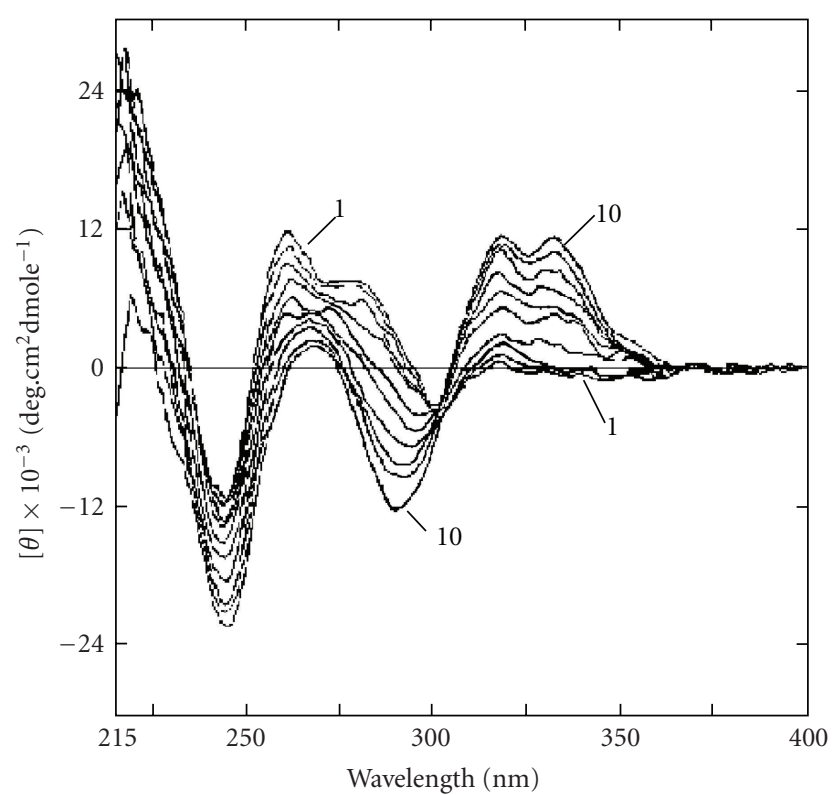

Figure 6: Circular dichroic spectrum of (1) $\mathrm{H}^{\mathrm{L}}$-DNA $(20 \mu \mathrm{M})$ with increasing concentrations up to $(20.64 \mu \mathrm{M})$ of coralyne (10). Reprinted from the PhD Thesis of K. Bhadra, [28].

that coralyne and berberine is able to stabilize rather than to induce G-quadruplex intermolecular structure. In both cases, coralyne is the most active component possibly due to its fully aromatic core and it is the most efficient telomerase inhibitor.

Among the benzophenanthridine alkaloids, sanguinarine, an isoquinoline plant alkaloid, is known to generate a wide variety of biochemical and pharmacological effects including its use in cancer prevention. The physical and molecular basis of the binding of sanguinarine with canonical B-DNA were first demonstrated by Maiti et al. [33, 34, 8488] using various physicochemical techniques like absorption, fluorescence, circular dichroism, thermal melting, viscometry, calorimetry, and NMR spectroscopy. On binding to B-DNA structures, the absorption spectrum of sanguinarine underwent bathochromic and hypochromic changes exhibiting clear isosbestic points (Figure $7(\mathrm{a})$ ), the steady-state fluorescence emission intensity quenched, thermal melting temperature of B-DNA shifted to higher temperatures and there were strong perturbations of circular dichroic pattern of B-DNA. Sanguinarine induced the unwinding process of covalently closed superhelical plasmid B-DNA with an unwinding angle of $27^{\circ}$. The binding of sanguinarine to calf thymus DNA was also investigated [39] by ${ }^{1} \mathrm{HNMR}$ and all the proton resonances in the molecule were assigned using a combination of 2D COSY, NOSEY, and ROSEY techniques. All these experiments conclusively suggested that it binds BDNA by a mechanism of intercalation [39]. The intercalative binding was subsequently supported by several authors [89-92]. The sequence selective binding of sanguinarine to B-DNA was also studied by Waring group [90] using DNAse foot printing technique and a mixed nucleotide sequence binding for sanguinarine-DNA complex formation was proposed. Recent calorimetric studies of sanguinarine calf thymus DNA complexation (Figure 7(b)) showed the binding process to be exothermic and enthalpy driven [57]. Binding and thermodynamic parameters of sanguinarinecalf thymus DNA complexation obtained from isothermal titration calorimetry are presented in Table 3. A recent study [93] showed that sanguinarine also binds to single pyrimidine bulges in hairpin sequences.

The interaction of sanguinarine with Z-DNA structure was first studied by Das et al. [94]. It was demonstrated that on addition of the alkaloid to the Z-form structure, a direct conversion of the Z-form toward the characteristic righthanded bound complex without forming any intermediate forms was observed. Sanguinarine bound strongly to Bform in a noncooperative manner while its binding to $\mathrm{Z}$ form was highly cooperative and $\sim 2-3$ base pairs of $Z$ form switched to the right-handed form for each bound sanguinarine molecule [94]. The interaction of sanguinarine with $\mathrm{H}^{\mathrm{L}}$-form showed that it does not bind to $\mathrm{H}^{\mathrm{L}}$-form structure, but it converted the structure to the bound righthanded $\mathrm{B}$-form $[94,95]$. Here also approximately 2-3 base pairs of the $\mathrm{H}^{\mathrm{L}}$-form switched to the right-handed bound $\mathrm{B}$ form for each bound molecule of sanguinarine.

Latimer et al. [96] first demonstrated that sanguinarine binds to $\operatorname{poly}(\mathrm{dT}) \cdot \operatorname{poly}(\mathrm{dA}) \operatorname{xpoly}(\mathrm{dT})$ but only weakly to poly $(\mathrm{dC}) \cdot \operatorname{poly}(\mathrm{dG}) \operatorname{xpoly}\left(\mathrm{dC}^{+}\right)$more quantitatively and reported that sanguinarine binds to triplexes by intercalation in a noncooperative manner and it stabilized the Hoogsteen base paired third strand of DNA compared to their Watson-Crick strands. Thermodynamic study revealed that the process of binding of sanguinarine to $\operatorname{poly}(\mathrm{dC}) \cdot \operatorname{poly}(\mathrm{dG}) \operatorname{xpoly}\left(\mathrm{dC}^{+}\right)$triplex was exothermic and enthalpy-driven while that to $\operatorname{poly}(\mathrm{dT}) \cdot \operatorname{poly}(\mathrm{dA}) \operatorname{xpoly}(\mathrm{dT})$ triplex was exothermic and entropy-driven. The binding constants and thermodynamic parameters of berberine, coralyne, and sanguinarine complexation to various triplexes are presented in Table 4. Recently, Bai et al. [97] reported that sanguinarine can form a complex with G-quadruplex telomere DNA as revealed from DNA polymerase stop assay, uv melting, electrospray mass spectroscopy, and circular dichroism studies which may potentiate a strategy for structure-based anticancer drug design targeting human telomeres.

2.2. Alkaloid-RNA Interactions. RNAs are versatile molecules that are now known to play an essential role in normal biological process and in the progression of several serious human diseases like HIV and Hepatitis C virus (HCV), and so forth which has led to growing interest in exploiting RNA as a cellular target for therapeutic drug design. The recent discovery of a number of micro RNAs and the knowledge of their functions further reiterated the critical and diverse roles played by RNA in cell biology $[98,99]$. Ribosomal RNA (r-RNA) has long been known to be the receptor for antibiotics and antisense oligonucleotides are being used to downregulate gene expression [100]. New drugs could potentially be designed to bind to unique structural regions in mRNA and thereby regulate gene expression. Virtually 


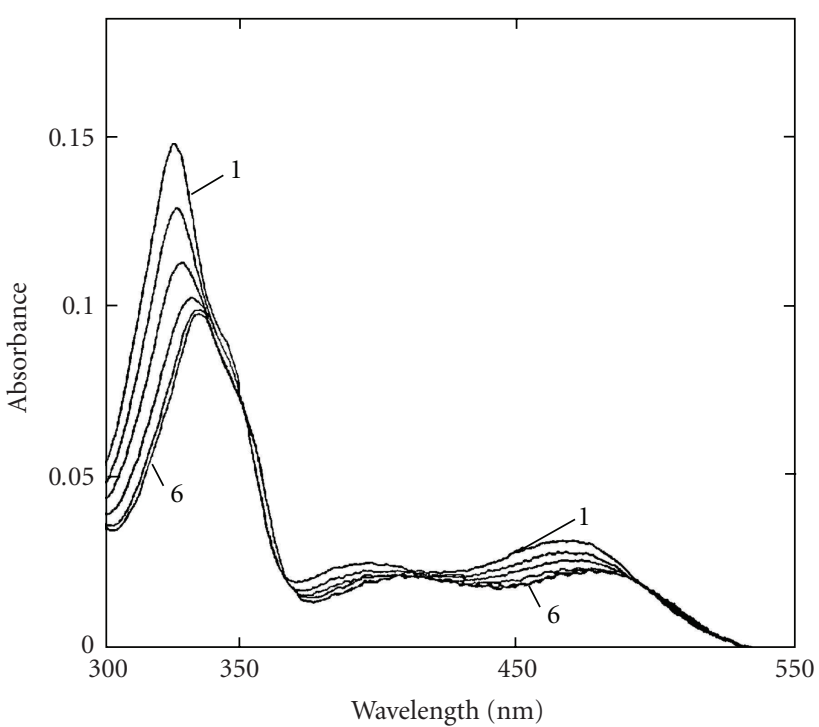

(a)

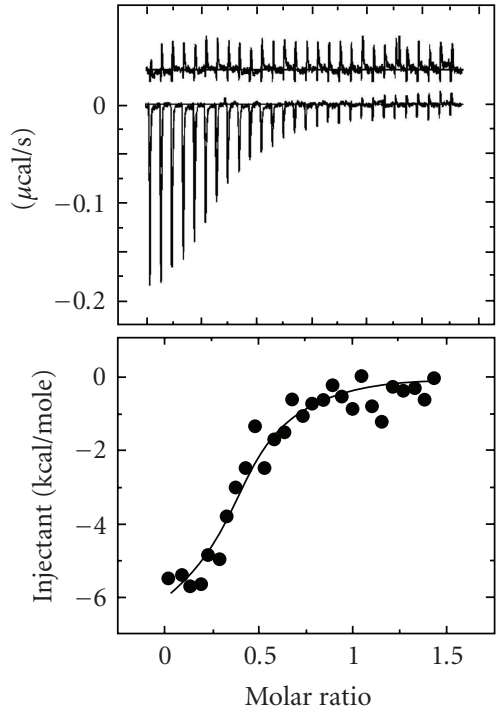

(b)

Figure 7: (a) Absorption spectrum (1) of sanguinarine $(4.9 \mu \mathrm{M})$ with increasing concentrations up to $54.8 \mu \mathrm{M}$ (10) of calf thymus DNA. Reprinted from the PhD Thesis of A. Das [71]. (b) The ITC profiles for the binding of sanguinarine (100 $\mu \mathrm{M})$ to Calf thymus DNA (15 $\mu \mathrm{M})$. The lower panel represents the corresponding normalized heat signals versus molar ratio. The data points reflect the experimental injection and the solid line represents the best fit of the data. Reprinted from the Ph.D. Thesis of Hossain [72].

all mRNAs formed in eukaryotic cells have a poly(A) tail of approximately 200-250 adenosines at the 3 'end. The long poly(A) tail is an important determinant of mRNA stability and maturation, and is essential for the initiation of transcription $[101,102]$ and the production of alternate forms of proteins $[103,104]$. The structure of poly(A) has been established to exist as a single-stranded helix stabilized by pair-wise stacking interaction between adjacent adenines at physiological $\mathrm{pH}$ and temperature $[105,106]$. $\operatorname{Poly}(\mathrm{A})$ polymerase (PAP) catalyses 3'-end poly(A) synthesis, participates in an endonucleolytic cleavage step and is one of the key factors in polyadenylation of the 3 'end of mRNA. Neo-PAP, a recently identified human PAP, is significantly overexpressed in human cancer cells in comparison to its expression in normal or virally transformed cells $[107,108]$ and may represent a tumor-specific target. Small molecules capable of recognizing and binding to the mRNA-poly(A) tail might interfere with full processing of mRNA by PAP and would represent a new type of potential therapeutic agent. In this context, several years ago Maiti et al. [76] first observed a preferential binding of berberine to poly(A) structure over B-DNA and tRNA and reported that the binding affinity of berberine to poly(A) was approximately 12 times higher than B-DNA and approximately 100 times higher than t-RNA molecules. Recently, they investigated the mode, mechanism, and energetics of berberine binding to $\operatorname{poly}(\mathrm{A})$ structure in details [109]. It was suggested that berberine binds strongly to single-stranded poly(A) structure by a mechanism of partial intercalation and the binding was found to be endothermic and entropy driven. Giri et al. [77] studied the interaction of palmatine with poly(A) using various biophysical techniques and their results also showed a strong affinity of palmatine to poly(A). The energetics of this strong binding of palmatine to poly (A) was found to be exothermic and enthalpy-driven [77].

Xing et al. [110] showed that coralyne binds to singlestranded poly(A) helix and induced the formation of a self-structure in poly(A). Depending on solution conditions such as $\mathrm{pH}$, salt and temperature, single-stranded poly(A) can adopt a parallel double stranded conformation formed by the pairing of adenine bases at the $\mathrm{N} 1$ position [111, 112]. The possibility of the formation of such a double stranded poly(A) in eukaryotic cells was hypothesized to result in the termination of the polyadenelation process [113]. Small molecules that could bind strongly to singlestranded poly(A) may be useful as potential leads for controlling the mRNA-poly(A) chain elongation and in turn mRNA degradation as well as the conversion of singlestranded poly(A) to double stranded poly(A) that may open up an opportunity for modulating nucleic acid structurefunctions. The plant alkaloids berberine and palmatine exhibit stronger binding to single stranded poly(A), but do not induce any self-structure formation in poly(A) helix $[109,114]$. Binding of coralyne to the poly $(\mathrm{A})$ helix leading to self structure formation was further supported by Giri and Kumar [79] and the binding process was found to be predominantly exothermic and enthalpy-driven with a stoichiometry of one coralyne per four adenines bases.

Sanguinarine was also found to bind very strongly to single stranded poly(A) $[71,78]$ and induce unique selfstructure in poly(A) [78]. The alkaloid binding process was exothermic and predominantly enthalpy-driven as revealed from isothermal titration calorimetry. Comparative circular dichroic spectrum of poly $(\mathrm{A})$ treated with various alkaloids 


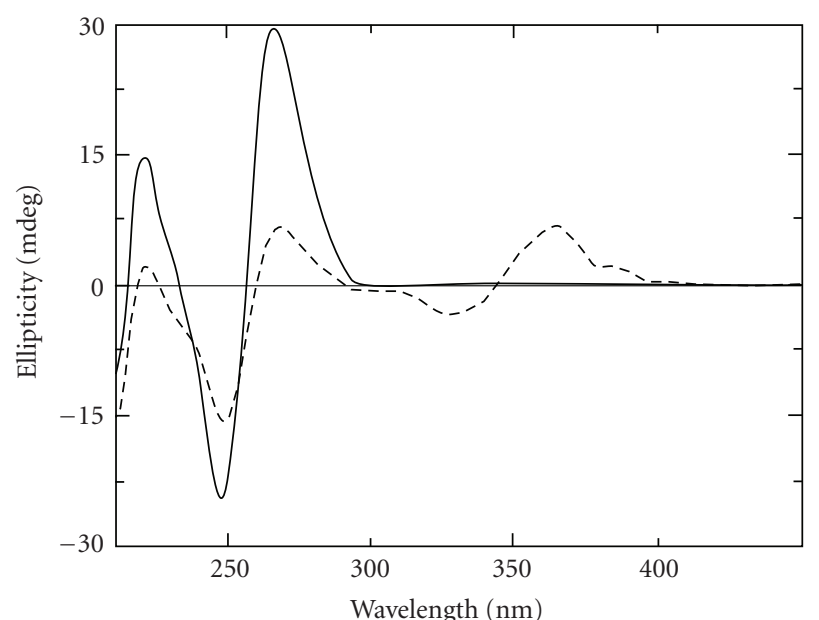

(a)

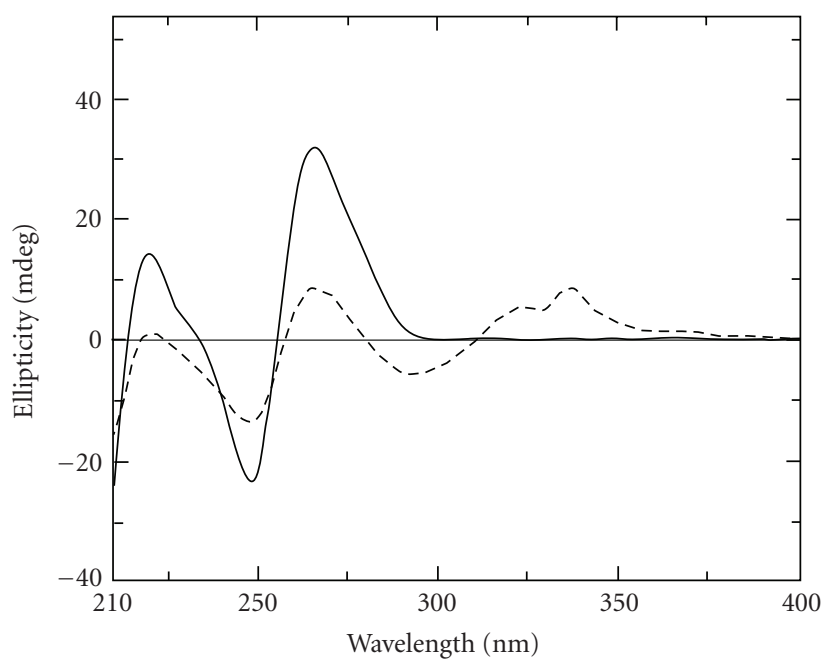

(c)

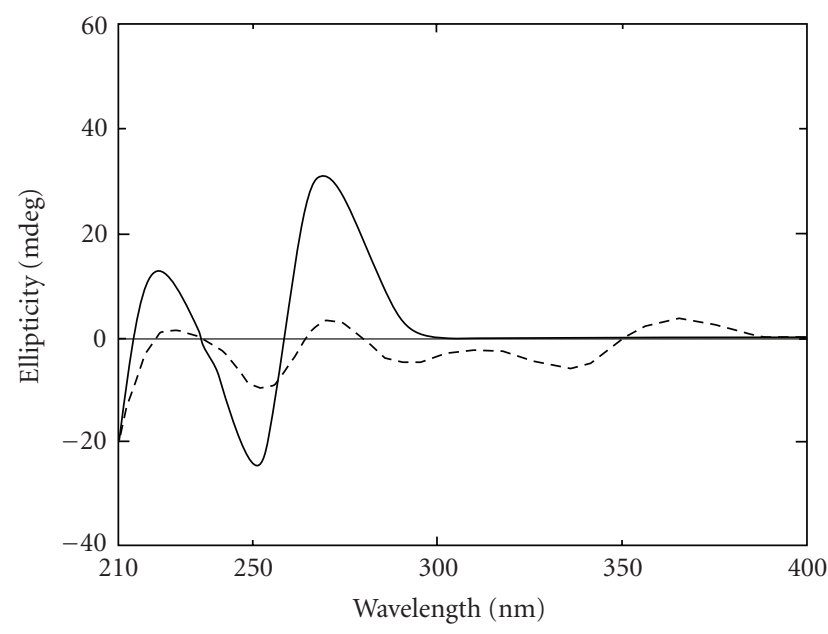

(b)

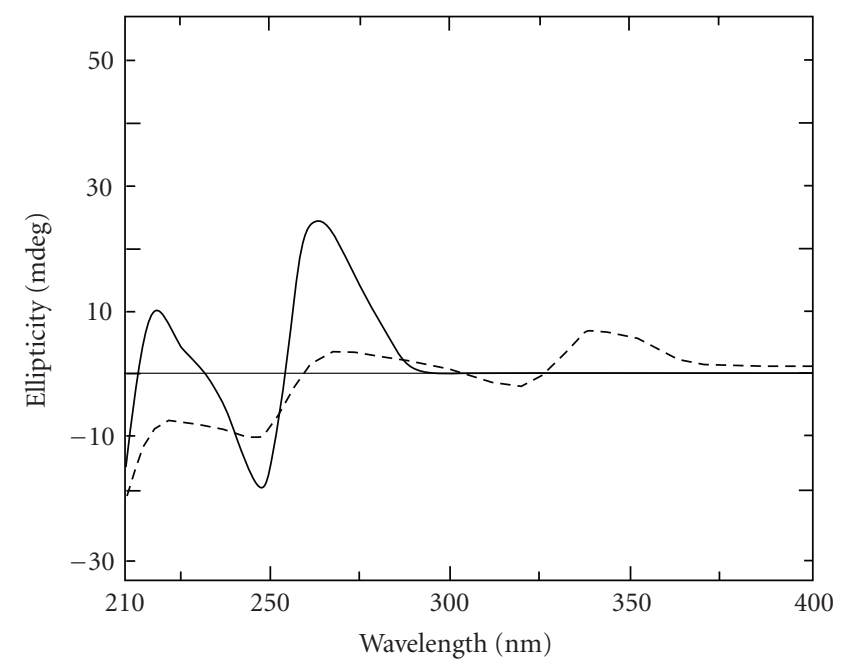

(d)

Figure 8: Circular dichroic spectrum of poly(A) helix (solid line) treated with (a) berberine (dashed line), (b) palmatine (dashed line), (c) coralyne (dashed line), and (d) sanguinarine (dashed line) at alkaloid/poly(A) molar ratio at saturation in each case. Partially reprinted from Nandi et al. [76], Giri et al. [77], Giri and Kumar [78], and Giri and Kumar [79] with permission from Elsevier.

are shown in Figure 8. Spectroscopic studies showed that among the four alkaloids, the affinity of binding of berberine, palmatine, and coralyne to poly(A) helix is one order lower than that of sanguinarine [116]. Thus, the very strong binding of sanguinarine to poly(A) leading to self structure formation may open up a new avenue for the use of this natural product in modulating the gene expression and development of anticancer agent.

\section{Topoisomerase Activity of Medicinal Alkaloids}

Topoisomerases are nuclear enzymes that act on the topology of DNA. It was first discovered by Wang [117]. There are three main types of DNA topology; supercoiling, knotting, and catenation. When outside of replication or transcription, DNA needs to be kept as compact as possible and these three states help this cause. However, when transcription or replication occurs, DNA needs to be free and these states seriously hinder the process. DNA toposiomerases are involved in the regulation of DNA supercoiling. Topoisomerase I (Topo I) changes the degree of supercoiling of DNA by causing single strand breaks and religation whereas topoisomerase II (Topo II) causes knotting, catenation and decatenation of DNA by passing the double-stranded DNA helix through a transient double-stranded break and then resealing in the strand break $[118,119]$. The difference roles of DNA Topo I and II may indicate an opposing pair of roles in the regulation of DNA supercoiling. Both activities are especially crucial during DNA transcription and replication, when the DNA helix must be unwound to allow proper function of large enzymatic machinery. Recently, two more topoisomerases have been discovered and these are namely topoisomerase III and topoisomerase IV. Topoisomerase III enzymes are implicated in regulation of recombination 
<smiles>COc1cc2c(cc1OC)-c1cc3ccc(OC)c(OC)c3c[n+]1CC2</smiles>

P1

(a)<smiles>COc1cc2cc3c4ccc(OC)c(OC)c4cc[n+]3cc2cc1OC</smiles>

P2

(b)<smiles>COc1cc2cc3c4ccc5c(c4cc[n+]3cc2cc1OC)OCO5</smiles>

P3

(c)<smiles></smiles>

(d)

Figure 9: Chemical structures of four palmatine derivatives.

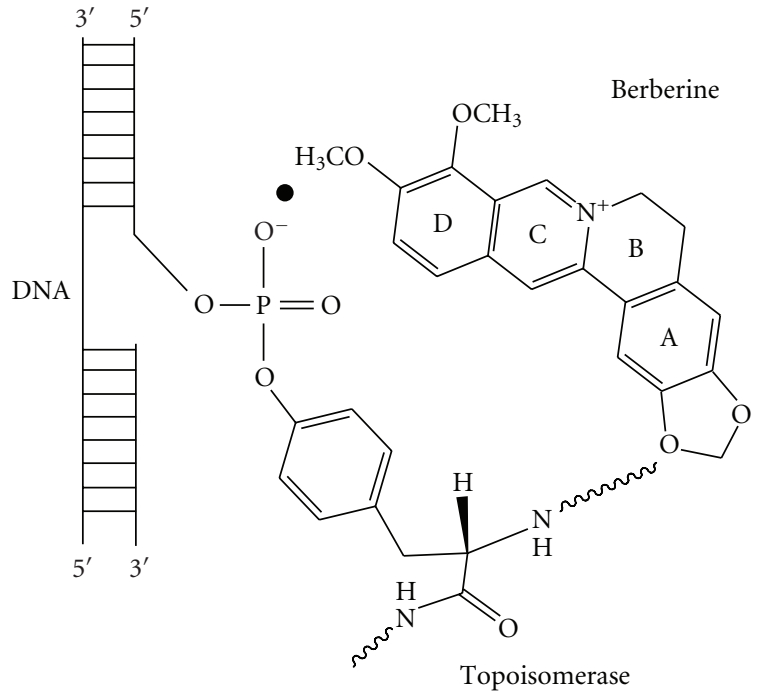

FIgURE 10: A schematic model of ternary complex formation of berberine on binding to Topo I and DNA.

events while topoisomerase IV has roles in the process of segregating newly replicated chromosomes [120].

DNA topoisomerases Topo I and Topo II represent the molecular target of many anticancer drugs. Fewer Topo I inhibitors have been discovered than Topo II inhibitors and a large number of them including the anthracyclines have been used as anticancer agents before identification of Topo II as their target. These inhibitors are chemotherapy agents designed to interfere with the action of topoisomerase enzymes that control the changes in DNA structure by catalyzing the breakage and rejoining of the phosphodiester backbone of DNA strands during the normal cell cycle. In recent years, topoisomerase inhibitors have become popular targets for cancer chemotherapy treatments. It is thought that topoisomerase inhibitors block the ligation step of the cell cycle, and that Topo I and Topo II inhibitors interfere with the transcription and replication of DNA by upsetting proper DNA supercoiling. Topo I has been established as an attractive molecular target for anticancer drugs, primarily due to the discovery of camptothecin (CPT) a naturally occurring plant alkaloid for its successful development as an anticancer drug with a unique mode of action, that is, inhibition of DNA Topo I, which added an entirely new dimension to the fields of chemotherapy [121]. Thus, developing compounds that are capable of poisoning the topoisomerases have emerged as an attractive approach for the search of novel cancer chemotherapeutic agents [122126]. For drugs $[127,128]$ that target Topo II intercalation into the host DNA duplex is strongly correlated with enzyme poisoning [129]. To understand the role that ligand-DNA interactions play in Topo I poisoning Li et al. [130] have characterized and cross correlated the Topo I poisoning and DNA binding properties of various families of structurally related DNA binding protoberberine alkaloids (Figure 9). These four analogues differ with respect to the chemical 
<smiles></smiles>

$\mathrm{C} 1$

(a)<smiles>[R]c1c2cc(OC)c(OC)cc2cc2c3cc(OC)c(OC)cc3cc[n+]12</smiles>

C3: $\mathrm{R}=\mathrm{H}$

C4: $\mathrm{R}=\mathrm{CH}_{2} \mathrm{CH}_{2} \mathrm{CH}_{3}$

C5: $\mathrm{R}=\mathrm{CH}_{2} \mathrm{CH}_{2} \mathrm{OH}$

C6: $\mathrm{R}=\mathrm{CH}_{2} \mathrm{CH}_{2} \mathrm{COOH}$

(c)<smiles></smiles>

C9: $\mathrm{R}=\mathrm{R}_{2}=\mathrm{CH}_{3} ; \mathrm{R}_{1}=\mathrm{R}_{3}=\mathrm{OCH}_{3}$ C10: $\mathrm{R}=\mathrm{CH}_{3} ; \mathrm{R}_{1}=\mathrm{R}_{2}=\mathrm{R}_{3}=-\mathrm{OCH}_{2} \mathrm{O}$ -

(e)<smiles>COc1cc2c(cc1OC)-c1cc3cc(OC)c(OC)cc3c(C)[n+]1CC2</smiles>

C2

(b)<smiles>[R]c1cc2cc3c4cc(OC)c(OC)cc4cc[n+]3c([R])c2cc1[R]</smiles>

C7: $\mathrm{R}=\mathrm{R}_{2}=\mathrm{H} ; \mathrm{R}_{2}=\mathrm{OCH}_{3}$

C8: $\mathrm{R}=\mathrm{H}, \mathrm{R}_{1}=\mathrm{OH}, \mathrm{R}_{2}=\mathrm{OCH}_{3}$

(d)<smiles>COc1cc2c(cc1OC)-c1cc3cc(OC)c(OC)cc3c[n+]1CC2</smiles>

(f)

FIGURE 11: Chemical structures of several coralyne derivatives.

substituents on their A- and D-rings. Their DNA binding data reveal that protoberberine alkaloids intercalate into duplex DNA while unwinding the host DNA by $13^{\circ}$. In addition, the data showed that modification of the D-ring alter both DNA binding affinity and Topo I poisoning activity. The modifications of the A-ring on the other hand have a negligible impact on DNA binding affinity but exerted a profound influence on Topo I poisoning activity. These structure-activity relationships are consistent with a model for Topo I poisoning by protoberberines in which both alkaloid-DNA and alkaloid-enzyme interactions are necessary for stabilization of the ternary (Topo I-DNAalkaloid) cleavable complex (Figure 10). It is suggested that an ensemble of both alkaloid-DNA and alkaloid-enzyme interaction may be of general importance for alkaloidinduced poisoning of Topo I.

Berberine, palmatine, and several of its derivatives were shown to act as mammalian Topo I and Topo II inhibitors although weakly [131], while coralyne and many of its derivatives were found to be strong inhibitors of DNA Topo I [132]. Both berberine and palmatine did not affect the DNA cleavage relegation reaction catalyzed by topoisomerases. 


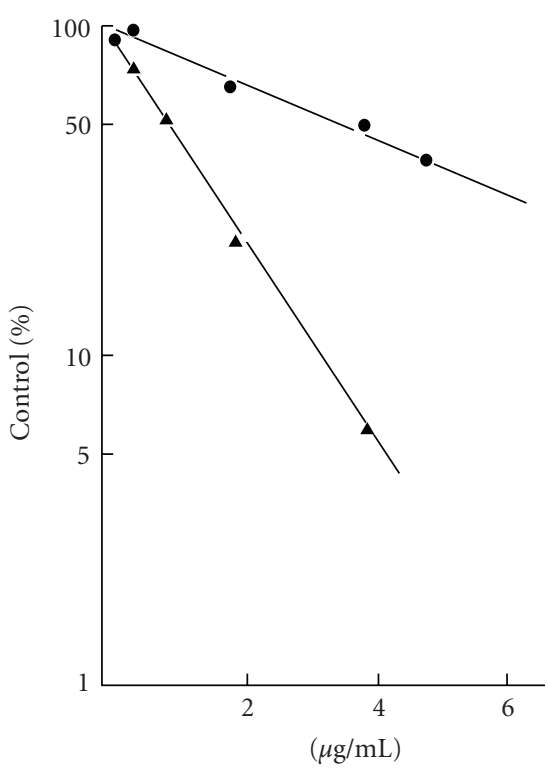

FIgURE 12: Effect of berberine on the incorporation of thymine $\left[{ }^{3} \mathrm{H}\right]$ into DNA $(-\bullet-)$ and glycine $\left[{ }^{13} \mathrm{C}\right]$ into protein $(-\boldsymbol{\Delta}-)$ by sarcoma S180 cancer cells in vitro. Reprinted from Creasey [80] with permission from Elsevier.

This lack of effect most likely accounts for the presence of a methoxy substituent at 9-position, which prevents hydrogen bonding interactions with guanine residues. The 9-position in berberine analogues is an important determinant for DNA topoisomerase II inhibition [131]. The most significant aspect of coralyne is its ability to inhibit DNA relaxation in a fashion significantly similar to the most potent antitumor alkaloid CPT [133]. Wang et al. [134] demonstrated that coralyne and several of its derivatives (Figure 11) including the partially saturated derivative, 5,6-dihydrocoralyne (C2) were tested for their ability to induce single-stranded cleavage by formation of ternary complexes with plasmid DNA and Topo I. It was observed that all the derivatives (C1-C11) induced cleavage in plasmid DNA but are not as effective as coralyne (C1) or 5,6-dihydrocoralyne (C2) and stabilize the complex between Topo I and DNA. However, coralyne (C1) was more effective than 5,6-dihydrocoralyne (C2) at lower concentration. In a subsequent study, Pilch et al. [40] confirmed that 8-desmethylcoralyne (C3) and 5,6-dihydro8-desmethylcoralyne (C11) may act as Topo I poison, whereas no Topo II poisoning properties were observed. More recent immunocytochemical studies in MCF-7 breast cancer cells showed that sanguinarine induces a striking disruption of normal cyclin and Topo II trafficking which inhibited the proliferation of transformed cells [135].

\section{Anticancer Properties of Isoquinoline Alkaloids}

Neoplastic disease is a global health problem. Although great attention is currently focused in unraveling the molecular, cellular, and genetic process that lead to cancer, this knowledge has not been translated into effective new cures

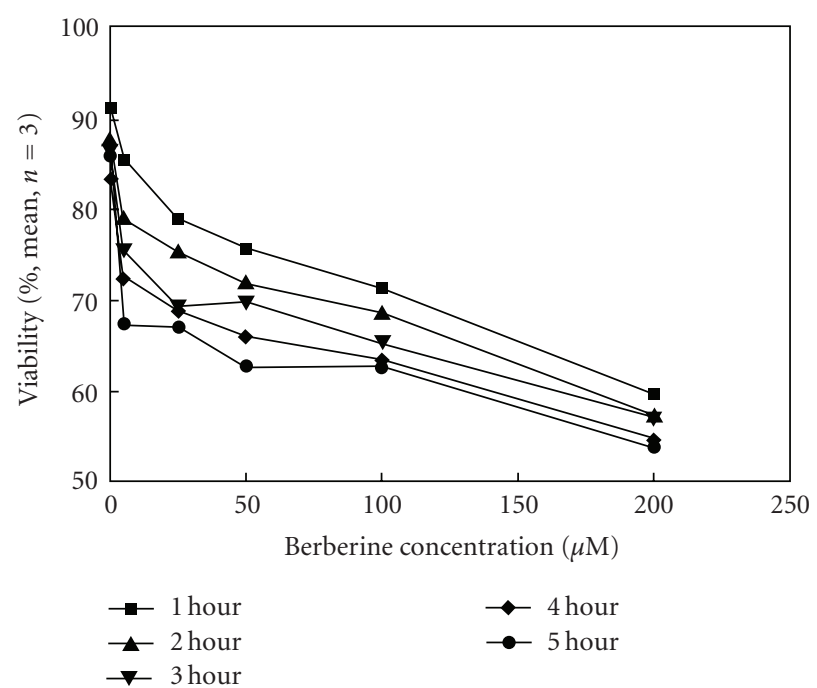

FIGURE 13: Viability of nasopharyngeal carinoma cells (NCP/HK1) after berberine treatment. Cells were incubated in different concentrations ( 5 to $200 \mu \mathrm{M}$ ) of berberine for 1 to 5 hours). Reprinted from Szeto et al. [115] with permission from Turkish Journal Medical Science with permission from the publishers.

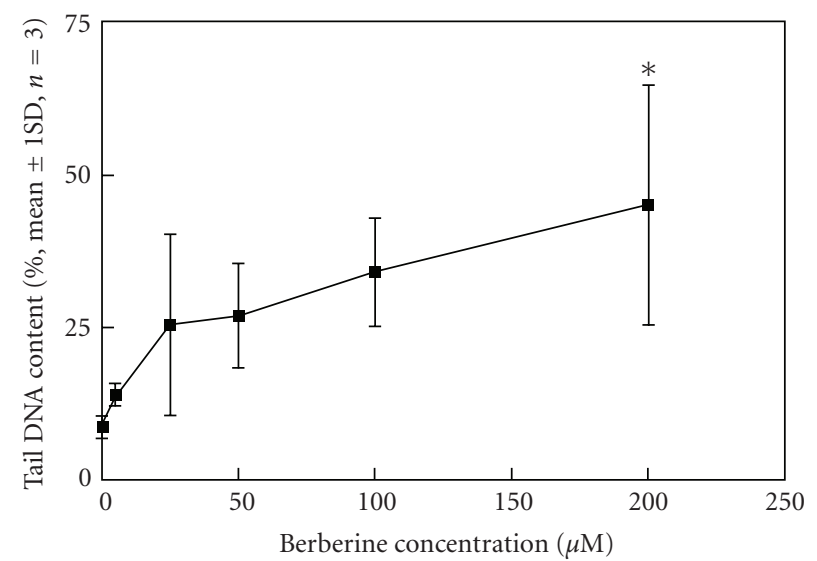

Figure 14: DNA damage of NCP/HK1 cells after 30 minutes. Treatment of berberine at different concentrations ( 5 to $200 \mu \mathrm{M}$ ). DNA damage was expressed in percentage of DNA content in the Comet tails. The results are mean \pm standard deviations of three individual experiments. Reprinted from Szeto et al. [115] with permission from the Turkish Journal Medical Science with permission from the publishers.

for the disease. Recent report of American Cancer Society (December 2007) showed that 7.6 million people died from various types of cancers. Apart from humans, other animals and plants may also be affected by cancer. In general, cancer defines diseases, in which abnormal cells divide without control that have the capacity to invade surrounding normal tissue, can spread to other parts of the body through the blood and lymph systems and kill the host in which it originates. For the last several years, it was observed that the incidence of some types of cancer increases with age. Therefore, as the life span of humans has increased, 


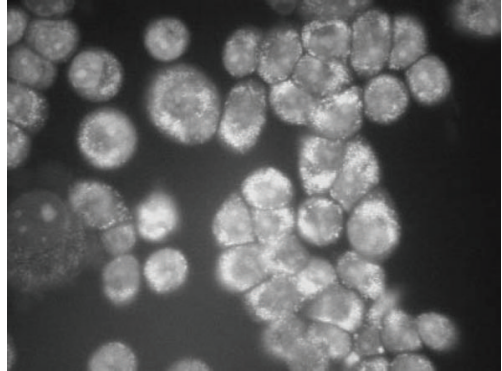

(a)

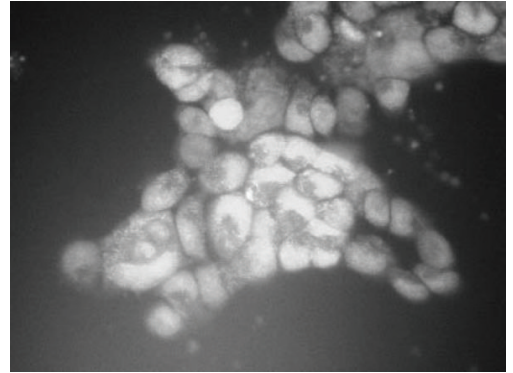

(b)

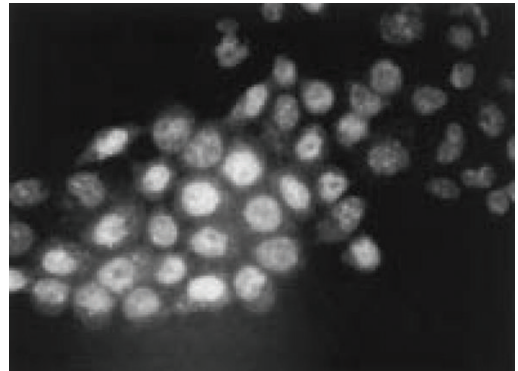

(c)

FIGURE 15: NCP/HK1 cells cultured on culture disk were incubated with $200 \mu \mathrm{M}$ of berberine for 2 to 46 hours. (a) Cells treated for 2 hours; (b) cells treated for 21 hours; (c) cells treated for 46 hours. Fluorescence indicated the presence of berberine. Reprinted from Szeto et al. [115] with permission from the Turkish Journal Medical Science with permission from the publishers.

the incidence of neoplastic diseases has also increased. There are several types of neoplastic diseases. Carcinoma is the cancer that begins in the skin or in tissues that line or cover internal organs. Sarcoma is the cancer that begins in bone, cartilage, fat, muscle, blood vessels, or other connective or supportive tissue. Leukemia is the cancer that starts in blood-forming tissue, such as bone marrow, and causes large numbers of abnormal blood cells either produce or enter the blood. Lymphoma and multiple myeloma are cancers that begin in the cells of the immune system. Central nervous system diseases are cancers that begin in the tissues of the brain and spinal cord. Adrenocortical carcinoma disease is cancer that forms in the outer layer of tissues of adrenal glands. Breast cancer forms in tissues of the breast, usually the ducts and lobules of women. Fibroids are common tumors of the uterus (womb) found in about $20 \%$ of young women and they form ball-like and may vary in size from pin to very large size. Although noncancerous, they can recur. Lung cancer is a disease that forms in tissues of the lung, usually in the cells living air passages. Tobacco smoking is associated with lung cancer and bladder cancer. Lung cancer is one of the leading causes of cancer-related death throughout the world. Despite of the advances in current therapeutic approaches for lung cancer, including surgery, radiotherapy, and chemotherapy, the overall survival rate of the patients with lung cancer has been static for the past two decades.

Improvement in curability and survival is dependent on advances in early detection, surgery, radiotherapy, and chemotherapy; but once widespread metastatic disease has become established, chemotherapy is a central component of management. Chemotherapy is the treatment of cancer with drugs (anticancer drugs) that can destroy cancer cells. In current usage, the term "chemotherapy" usually refers to cytotoxic agents that affect rapidly dividing cells in general [136]. Several antitumor antibiotics and plant alkaloids are the more recent clinically effective antitumor cytotoxic drugs, which act by disrupting the structure of duplex BDNA, thereby affecting their interaction with proteins that are important in DNA replication, repair, or transcription. Investigation into the mechanism of action of plant-

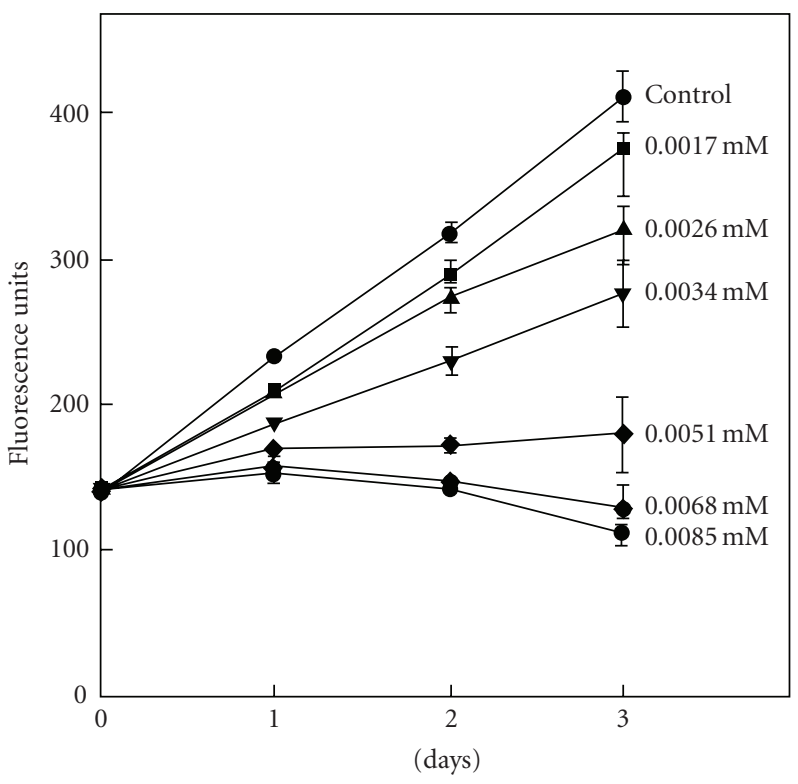

FIGURE 16: Time course of Smulow-Glickman (S-G) gingival cells growth to a continuous three-day exposure to sanguinarine. Cellular DNA was estimated with the fluorochrome, Hoechst 33258 using an excitation wavelength of $360 \mathrm{~nm}$ and emission wavelength of $460 \mathrm{~nm}$. Reprinted from Babich et al. [137] with permission from John Wiley and Sons Inc.

derived compounds with low toxicity remains an important approach in the search for new and more effective anticancer agents.

Protoberberine and benzophenanthridine group of alkaloids possessing broad range of biological activity [138146] are widely distributed in several botanical families and are used in traditional Chinese and ayurvedic medicine for many centuries. This review is restricted to their anticancer properties currently studied in several laboratories. Berberine is found in the roots of rhizomes of several families of plants; Goldenseas, Coptin, Oregon grapes, Barberry, Tree turmeric, Yerba mansa, among others and possess antitumor 
activities [147, 148]. It exhibits potent in vitro antitumor activity against Sarcoma S180 cells with inhibition of the biosynthesis of DNA, RNA, and proteins [80]. It was evident that berberine interfered with all these biochemical process (Table 5). However, the synthesis of RNA and protein was most sensitive to the alkaloid at $40 \mathrm{ug} / \mathrm{mL}$. DNA and protein biosynthesis were examined further by incorporation of thymidine $\left[{ }^{3} \mathrm{H}\right]$ into DNA and glycine $\left[{ }^{14} \mathrm{C}\right]$ into protein in S180 cells in vitro and dose response curves was shown in Figure 12. Creasey [80] reported that the in vivo 30minutes treatment with berberine on tumor bearing mice $(10 \mathrm{mg} / \mathrm{kg})$ before injection of thymidine $\left[{ }^{3} \mathrm{H}\right]$ or glycine $\left[{ }^{14} \mathrm{C}\right]$ had only minimal effects on the incorporation of these precursors into DNA and protein, respectively, and inhibition was found to be only $17 \%$ for protein and $14 \%$ for DNA. However, when cells were harvested 30 minutes after treatment with berberine and then incubated with glycine $\left[{ }^{14} \mathrm{C}\right]$ and thymine $\left[{ }^{3} \mathrm{H}\right]$ in vitro incorporation into protein and DNA (Figure 12) was reduced by $85 \%$ and $45 \%$, respectively. Kuo et al. [149] observed an increase of G2/M phase population in berberine-treated HL60 cells. It modulates expression of mdrl gene product in track cancer cells [150] and was identified as a potential inhibitor for caspase 3 , a major apoptosis effector [151]. It was also reported that berberine downregulates K-Ras 2 gene expression in human embryonic carcinoma cells [152]. Apoptosis-induced by berberine was found in cancer L1210 and U937 cells [153]. Wu et al. [154] demonstrated that berberine-induced apoptosis of human leukemia HL60 cells with downregulation of nucleophosmin/B23 and telomerase activity. Li et al. [130] linked its cytotoxic activity to a duel Topo I and Topo II poisoning activity. For management of skin cancers, Montena et al. [155] for the first time demonstrated in vitro treatment of human epidermoid carcinoma A431 cells with berberine that decreased cell viability, induced cell death in dose-dependent manner which was associated with an increase in G1 arrest and suggested berberine to be used as chemotherapeutic drug against human epidermoid carcinoma A431 cells. The effect of berberine on human malignant brain tumor esopharyngeal cancer and human leukemic and human colon cancer cell lines was tested, where a significant killing effect was achieved [156, 157]. Subsequently, Szeto et al. [115] investigated the cytotoxicity and the DNA damage effect on NPC/HK-1 cells after berberine treatment and evaluated the possibility of DNA repair in this cell line. Their studies showed that berberine, at 5-200 $\mu \mathrm{M}$ induced cell death in a dose dependent manner. Treatment of cells with $200 \mu \mathrm{M}$ berberine for 5 hours yielded $60 \%$ drop of cell viability (Figure 13). The Comet assay was employed after berberine treatment ( 5 to $200 \mu \mathrm{M}$ ). The mean tail DNA content increased as berberine concentration increased (Figure 14). DNA damage was evident within 30 minutes and was more pronounced after 1.5 hours. The damaged cells were not able to be repaired as indicated by the increase in tail DNA content (Figure 14). Furthermore, berberine was observed mainly in the cytoplasmic region of NPC cells at 2 hours of incubation at $200 \mu \mathrm{M}$ as examined under a fluorescent microscope (Figure 15). Again, berberine has been found [158] to be near the nuclear region and able to bind with DNA and may inhibit DNA topoisomerase II. Therefore, inhibition of DNA repair ability and stability may also contribute to the cytotoxic effect on the cancer cells. The DNA damaging effect and the inhibition of DNA repair contributed to the cytotoxic activity in the cancer cells may be part of the mechanisms of action of berberine on cancer cells. Berberine also displayed alterations in cell cycle progression, DNA synthesis, cell proliferation, and cell death in melanoma cells K1735-M2 mouse and WM 793 human melanoma malignant cell lines which were correlated with the concentration and intracellular distribution of the alkaloid and suggested that it may be used in clinical development of a cytotoxic compound [159]. Moreover, berberine was shown to inhibit telomere elongation [67], and bind to various human G-quadruplex structures inhibit telomerase [67]. Berberine has been found to be useful for the treatment of lung cancer patients [160] and the correlation between the overexpression of AP-I and lymphatic metastasis has been reported [161]. Combined treatment with berberine and an anticancer drug camptothecin analogue, CPT-II resulted in a marked inhibition of the tumor growth at the implantation site and of lymphatic metastasis, as compared with either treatment alone [162]. Berberine also exhibited dose-dependent antiproliferative effects of the human promonocytic U937 cells and induced significant changes in mitochondrial membrane potential of the tumor cells [163]. In a recent study [164], the effects of berberine on the human promyclocytic leukemia HL60 cells and on the murine mylomonocytic leukemia WEH13 cells suggested berberine induced G2/M arrest in both the cells via the inhibition of cyclin B1 and the promotion of Wee1. The treatment of human prostate cancer cells (PC-3) with berberine revealed that berberine-mediated cell death of human prostate cancer cells was regulated by reactive oxygen species and suggested that berberine may be considered as a promising therapeutic candidate for prostate cancer [165].

Berberine was assessed for the anti-human cytomegalovirus (HCMV) activity using the plaque assay. It was suggested [166] that berberine inhibited the replication of HCMV that was presumed to interfere with intracellular events after virus penetration into the host cells and before viral DNA synthesis. Berberine showed inhibition of reverse transcriptase activity of RNA tumor viruses and the results were correlated with its antileukemic activity [167]. The enzyme cyclooxygenase- $Z$ (COX-2) is abundantly expressed in colon cancer cells [168] and plays a key role in colon tumerogensis [169]. Compounds inhibiting COX-2 transcriptional activity have therefore potentially a chemopreventive property against colon tumor formation. Fukuda et al. [170] have reported that berberine effectively inhibits COX-2 transcriptional activity in colon cancer cells in a dose-dependent manner at concentrations higher than $0.3 \mu \mathrm{M}$. The inhibitory activity of berberine on COX-2 promotor activity is not simply due to the direct inhibition of macromolecular synthesis in the cells. In addition, reactive oxygen intermediates play a role in the expression of COX-2 [171] and COX-2 promotor activity is regulated by interactions of diverse transcription factors and 
intracellular messages [172]. It has been reported that COX-2 overexpression is associated with the acquisition of resistance to apoptosis in intestinal epithelial cells [173]. Berberine exhibits cytostatic and cytocidal effects in various cell lines. It is likely that inhibition of COX-2 promotor activity may be associated with antitumor and cytostatic/cytocidal effects of berberine.

Palmatine has been found in the roots, rhizomes, and stem bark of many species of berberidaceae, papaveraceae, fumararaace, menispermaceae, rutaceae, raunculaece, and other plant family. Palmatine has been used as folk medicine for centuries due to its immense pharmacological properties. The medicinal plants containing palmatine have been used in the treatment of jaundice, dysentery, hypertension, inflammation, and liver diseases [174, 175].

Coralyne has been shown to exhibit significant antileukemic activity against both P388 and 11210 leukemia cells in mice $[74,176]$. Although its antitumor activity is not very high, coralyne represents a promising lead structure because of its low toxicity [177, 178]. It was shown that irradiation of superhelical plasmid DNA in the presence of coralyne leads to an efficient single-stranded cleavage even upon exposure to sunlight. Thus photodamaging properties of coralyne may offer a useful tool for the DNA damage. Again, the photoinduced cleavage may be used for the introduction of DNA lesions in triplex and quadruplex DNA because coralyne exhibits a remarkable propensity to bind to these higher-order DNA structures [67, 68, 81]. In particular, the photoinduced damage of the triplex DNA may be of interest to those therapeutic approaches in which the selective attack of triplex DNA is the key process.

The quaternary benzophenanthridine alkaloids which are mainly distributed in the plants of the Papaveraceae, Rutaceae, Fumariaceae families have been the focus of increasing attention for their diverse biological activities. Among this group of alkaloids, sanguinarine possesses potent anticancer [179-182], promising apoptosis activities [181], as well as cytotoxic effects [183]. In fact, the plants containing sanguinarine have been widely used as Chinese medicines and folk medicines for the treatment of human cancer and other diseases. In the UK and USA, sanguinarine has been in use in mouthwashes and toothpastes to inhibit dental plaque and inhibit gingival health [184]. The potential anticancer activities of sanguinarine may be attributed to its binding of chromosomal DNA. Studies have revealed that in physiological conditions, both iminium and alkanolamine forms of the alkaloid exist because they all exhibit $\mathrm{pH}$ dependent structural equilibrium between these two forms [87, 88, 185]. Alkanolamine form was reported to have larger cellular availability than iminium form due to its greater lipophilicity [186]. Maiti et al. [85] studied the interaction of sanguinarine with B-DNA under various environmental conditions ie salt molarity, $\mathrm{pH}$, etc. and suggested that sanguinarine may be useful as a potential antitumoral agent. This proposal was found to be true when an in vitro study of cytotoxicity of sanguinarine using cancer cell lines and primary cells from oral human tissues established the potential use of sanguinarine for the inhibition of growth of S-G gingival epithelial cells and $\mathrm{KB}$ carcinoma cells, and correlated with its complex formation with DNA [137]. Babich et al. [137] studied the effect of sanguinarine on proliferation of the S-G cells exposed for 1 to 3 days as shown in Figure 16. It was noted that linear increase in growth was significantly affected with increasing concentration of sanguinarine and no growth was observed after 3 days of exposure to sanguinarine at $5.1 \mu \mathrm{M}$ or greater concentration. As assessed by DNA quantification, S-G-cells maintained continuously inhibition of growth increasing concentration of sanguinarine from $1.7 \mu \mathrm{M}$ to $8.5 \mu \mathrm{M}$ may reflect the ability of sanguinarine to intercalate DNA. Sanguinarine has been reported to possess the potential for selective/preferential elimination of cancer cells without affecting normal cells $[180,187]$. The study of differential effects [188] of the alkaloid upon cell viability, DNA damage, and nucleus integrity in mouse primary spleen cells and mouse lymphocytic leukemic cells L1210 showed that sanguinarine produces dose-dependent increase in DNA damage and cytotoxicity in both cells. In contrast to primary mouse spleen cells, leukemic L1210 cells showed slightly higher sensitivity to sanguinarine, suggesting that cytotoxic and DNA damaging effects of sanguinarine are more selective against mouse leukemic cells and primary mouse spleen cells [188]. Han et al. [189] investigated the possible mechanism through which sanguinarine exerts its antiproliferative action in cultured rat glioblastoma cells and suggested the induction of apoptosis to be due to the downregulation of the extra cellular signal regulated kinase and Akt signaling pathway. The effect of sanguinarine on the human cells line HeLa (Cervix carcinoma cells) has been studied [190] and the results showed a strong killing effect of sanguinarine which was explained as a consequence of its easy penetration through cell membrane owing to nonpolar pesudobase formation and to a high degree of molecular planarity. Primary effusion lymphoma [PEL] is an incurable, aggressive B-cell malignancy that develops rapid resistance to conventional chemotherapy. It was established [191] that sanguinarine inhibits cell proliferation and induces apoptosis in a dose dependent manner in several PEL cell lines and suggested that the alkaloid is a potent inducer of apoptosis of PEL cells via upregulation of death receptor 5 and raise the possibility that sanguinarine may be of value in the development of novel therapeutic approaches for the treatment of PEL cells. To investigate sanguinarine sensitivity in neuroendocrine tumor cell lines (human pancreatic carcinoid and human bronchial carcinoid cells), Larsson et al. reported [192] that these tumor cell lines are very much sensitive to sanguinarine, which may be used, in clinical trials and show therapeutic effect in patients with neuroendocrine tumors. A recent study showed [193] that treatment of human breast cancer MDA-231 cells with sanguinarine induced remarkable apoptosis accompanying the generation of reactive oxygen species leading to cell death. Very recently Matkar et al. [194] studied the effect of sanguinarine in human colon cancer cell-line and showed its ability to cause DNA single and double stranded break as well as increased level of 8oxodeoxyguanosine and reported DNA damage consistent with colon cancer cell death. 


\section{Conclusions and Perspectives}

The use of plants as medicines by human dates back to several thousand years. Alkaloids of plant origin are natural products that exhibit a myriad of biological and pharmacological properties. In view of their extensive occurrence in nature and significantly low toxicities, prospective development and use of these alkaloids as anticancer drugs are matters of great current interest. This review has focused on nucleic acid binding properties and topoisomerase inhibitory activities of some important representatives of the protoberberine (berberine, palmatine, and coralyne) and benzophenanthridine (sanguinarine) groups of alkaloids and their derivatives in relation to their role in cancer.

A large amount of published data suggests that all these alkaloids bind to various polymorphic DNA and also to single stranded poly(A) structures as evidenced from diverse biophysical techniques. Berberine and palmatine bind to the B-form DNA by partial intercalation. On the other hand, berberine binds to left-handed Hoogsteen base paired $\mathrm{H}^{\mathrm{L}}$-form DNA suggesting the effective use of berberine as sensitive probes to detect handedness change in DNA on protonation but it does not bind to left-handed WatsonCrick base paired Z-form. Coralyne on the other hand exhibits strong binding to duplex B-form DNA and single stranded poly(A) structure by mechanism of intercalation as well as it induces self-structure formation on binding to single stranded poly(A). Again, berberine and coralyne have the ability to induce and stabilize DNA triplexes and G-quadruplex structures (including human G-quadruplex) as well. Their efficiency in inhibiting telomerase and topoisomerase activity may potentiate their use as potential anticancer drugs. The alkaloid sanguinarine is known for its anticancer/antitumor properties and possesses the potential for selective/preferential elimination of cancer cells. It binds to B-form duplex DNA and single stranded poly (A) structure very strongly by intercalation and it induces the conversion of single stranded poly(A) to double-stranded poly(A) on binding. Sanguinarine does not bind to $\mathrm{Z}$-form or $\mathrm{H}^{\mathrm{L}}$ form but it converts both $\mathrm{Z}$-form and $\mathrm{H}^{\mathrm{L}}$-form DNA to bound B-form structure. It also formed a strong complex with triplex DNA that may lead to its use in triplextargeted cancer therapy. Sanguinarine has been shown to stabilized the intramolecular DNA G-quadruplex formed in human teleomeric sequence (tandem d(TTAGGG) repeats) and to inhibit the activity of telomerase and teleomere maintenance. Thus, sanguinarine may be considered as a useful molecule for cancer therapeutic action. The striking aspect here is that the specific binding of all these alkaloids to single-stranded adenine regions of the mRNA-poly(A) tail could interfere in mRNA processing by human PAP to be significantly overexpressed in human cancer cells and may emerge as new type of RNA based therapeutic agents for cancer diseases. Thus, the differential binding of these alkaloids to various polymorphic nucleic acid conformations with specific biological functions may potentiate their use in nucleic acid-targeted drug design that in turn may convey some specific meaning for their regulatory roles in neoplastic diseases.

\section{Acknowledgments}

M. Maiti thanks the Council of Scientific and Industrial Research (Government of India) for Emeritus Scientist award. The authors gratefully acknowledge the contributions of all the erstwhile and current researchers of the Biophysical Chemistry Laboratory for their contribution to the understanding of alkaloid-nucleic acids interactions.

\section{References}

[1] M. J. Waring, "DNA modification and cancer," Annual Review of Biochemistry, vol. 50, pp. 159-192, 1981.

[2] L. H. Hurley, "Secondary DNA structures as molecular targets for cancer therapeutics," Biochemical Society Transactions, vol. 29, no. 6, pp. 692-696, 2001.

[3] J. D. Watson and F. H. C. Crick, "Molecular structure of nucleic acids: a structure for deoxyribose nucleic acid," Nature, vol. 171, no. 4356, pp. 737-738, 1953.

[4] P. Belmont, J.-F. Constant, and M. Demeunynck, "Nucleic acid conformation diversity: from structure to function and regulation," Chemical Society Reviews, vol. 30, no. 1, pp. 7081, 2001.

[5] G. M. Blackburn and N. J. Gait, Nucleic Acids in Chemistry and Biology, IRL Press, Oxford, UK, 1990.

[6] W. D. Wilson and K. Li, "Targeting RNA with small molecules," Current Medicinal Chemistry, vol. 7, no. 1, pp. 73-98, 2000.

[7] J. Gallego and G. Varani, "Targeting RNA with smallmolecule drugs: therapeutic promise and chemical challenges," Accounts of Chemical Research, vol. 34, no. 10, pp. 836-843, 2001.

[8] Q. Vicens and E. Westhof, "RNA as a drug target: the case of aminoglycosides," ChemBioChem, vol. 4, no. 10, pp. 10181023, 2003.

[9] J. B. Chaires, Drug-Nucleic Acid Interactions, Academic Press, New York, NY, USA, 2001.

[10] T. R. Krugh, "Drug-DNA interactions," Current Opinion in Structural Biology, vol. 4, no. 3, pp. 351-364, 1994.

[11] H. Ihmels, K. Faulhaber, D. Vedaldi, F. Dall'Acqua, and G. Viola, "Intercalation of organic dye molecules into doublestranded DNA — part 2: the annelated quinolizinium ion as a structural motif in DNA intercalators," Photochemistry and Photobiology, vol. 81, no. 5, pp. 1107-1115, 2005.

[12] D. E. Graves and L. M. Velea, "Intercalative binding of small molecules to nucleic acids," Current Organic Chemistry, vol. 4, no. 9, pp. 915-929, 2000.

[13] Z. Taira, S. Kanzawa, C. Dohara, S. Ishida, M. Matsumoto, and Y. Sakiya, "Intercalation of six $\beta$-carboline derivatives into DNA," Japanese Journal of Toxicology and Environmental Health, vol. 43, no. 2, pp. 83-91, 1997.

[14] R. D. Estensen, A. K. Krey, and F. E. Hahn, "Studies on a deoxyribonucleic acid-quinine complex," Molecular Pharmacology, vol. 5, no. 5, pp. 532-541, 1969.

[15] M. Maiti and G. S. Kumar, "Molecular aspects on the interaction of protoberberine, benzophenanthridine, and aristolochia group of alkaloids with nucleic acid structures and biological perspectives," Medicinal Research Reviews, vol. 27, no. 5, pp. 649-695, 2007.

[16] M. Maiti and G. S. Kumar, "Protoberberine alkaloids: physicochemical and nucleic acid binding properties," in 
Bioactive Heterocycles IV, M. T. H. Khan, Ed., vol. 10 of Topics in Heterocyclic Chemistry, pp. 155-209, Springer, Berlin, Germany, 2007.

[17] R. Martínez and L. Chacón-García, "The search of DNAintercalators as antitumoral drugs: what it worked and what did not work," Current Medicinal Chemistry, vol. 12, no. 2, pp. 127-151, 2005.

[18] W. A. Denny, "DNA-intercalating ligands as anti-cancer drugs: prospects for future design," Anti-Cancer Drug Design, vol. 4, no. 4, pp. 241-263, 1989.

[19] T. C. Birdsall and G. S. Kelly, "Berberine: therapeutic potential of an alkaloid found in several medicinal plants," Alternative Medicine Review, vol. 2, no. 2, pp. 94-103, 1997.

[20] R. Verporte, "Antimicrobially active alkaloids," in Alkaloids, Biochemistry, Ecology and Medicinal Applications, M. F. Roberts and M. Wink, Eds., pp. 397-433, Plenum Press, New York, NY, USA, 1998.

[21] K. S. Kornman, "Antimicrobial agents," in Dental Plaque Control Measures and Oral Hygiene Practices, H. Löe and D. V. Kleinman, Eds., pp. 121-142, IRL Press, Oxford, UK, 1986.

[22] A. H. Amin, T. V. Subbaiah, and K. M. Abbasi, "Berberine sulfate: antimicrobial activity, bioassay, and mode of action," Canadian Journal of Microbiology, vol. 15, no. 9, pp. 10671076, 1969.

[23] K. Inoue, U. Kulsum, S. A. Chowdhury, et al., "Tumorspecific cytotoxicity and apoptosis-inducing activity of berberines," Anticancer Research, vol. 25, no. 6, pp. 40534059, 2005.

[24] I. D. Mandel, "Antimicrobial mouthrinses: overview and update," The Journal of the American Dental Association, vol. 125, supplement 2, pp. 2S-10S, 1994.

[25] Z. Ding, S.-C. Tang, P. Weerasinghe, X. Yang, A. Pater, and A. Liepins, "The alkaloid sanguinarine is effective against multidrug resistance in human cervical cells via bimodal cell death," Biochemical Pharmacology, vol. 63, no. 8, pp. 14151421, 2002.

[26] J. Huh, A. Liepins, J. Zielonka, C. Andrekopoulos, B. Kalyanaraman, and A. Sorokin, "Cyclooxygenase 2 rescues LNCaP prostate cancer cells from sanguinarine-induced apoptosis by a mechanism involving inhibition of nitric oxide synthase activity," Cancer Research, vol. 66, no. 7, pp. 3726-3736, 2006.

[27] K. Bhadra, M. Maiti, and G. S. Kumar, "Berberine-DNA complexation: new insights into the cooperative binding and energetic aspects," Biochimica et Biophysica Acta, vol. 1780, no. 9, pp. 1054-1061, 2008.

[28] K. Bhadra, Polymorphic nucleic acid structures and their interaction with isoquinoline alkaloids, Ph.D. thesis, Jadavpur University, Kolkata, India, 2007.

[29] L. Grycova, J. Dostal, and R. Marek, "Quaternary protoberberine alkaloids," Phytochemistry, vol. 68, no. 2, pp. 150-175, 2007.

[30] D. Debnath, G. S. Kumar, R. Nandi, and M. Maiti, "Interaction of berberine chloride with deoxyribonucleic acids: evidence for base and sequence specificity," Indian Journal of Biochemistry and Biophysics, vol. 26, no. 4, pp. 201-208, 1989.

[31] K. Bhadra, M. Maiti, and G. S. Kumar, "Interaction of isoquinoline alkaloid palmatine with deoxyribonucleic acids: binding heterogeneity, and conformational and thermodynamic aspects," Chemistry and Biodiversity, vol. 5, no. 4, pp. 575-590, 2008.

[32] S. Pal, G. S. Kumar, D. Debnath, and M. Maiti, "Interaction of the antitumour alkaloid coralyne with duplex deoxyribonucleic acid structures: spectroscopic and viscometric studies,"
Indian Journal of Biochemistry and Biophysics, vol. 35, no. 6, pp. 321-332, 1998.

[33] M. Maiti, R. Nandi, and K. Chaudhuri, "Sanguinarine: a monofunctional intercalating alkaloid," FEBS Letters, vol. 142, no. 2, pp. 280-284, 1982.

[34] M. Maiti, R. Nandi, and K. Chaudhuri, "Interaction of sanguinarine with natural and synthetic deoxyribonucleic acids," Indian Journal of Biochemistry and Biophysics, vol. 21, no. 3, pp. 158-165, 1984.

[35] L. Michaelis, "The nature of the interaction of nucleic acids and nuclei with basic dyestuffs," Cold Spring Harbor Symposium on Quantitative Biology, vol. 12, pp. 131-142, 1947.

[36] M. Maiti and K. Chaudhuri, "Interaction of berberine chloride with naturally occurring deoxyribonucleic acids," Indian Journal of Biochemistry and Biophysics, vol. 18, no. 4, pp. 245-250, 1981.

[37] G. S. Kumar, D. Debnath, and M. Maiti, "Conformational aspects of poly(dI-dC).poly(dI-dC) and poly(dG$\mathrm{dC})$.poly (dG-dC) on binding of the alkaloid, berberine chloride," Anti-Cancer Drug Design, vol. 7, no. 4, pp. 305314, 1992.

[38] G. S. Kumar, D. Debnath, A. Sen, and M. Maiti, "Thermodynamics of the interaction of berberine with DNA," Biochemical Pharmacology, vol. 46, no. 9, pp. 1665-1667, 1993.

[39] A. Saran, S. Srivastava, E. Coutinho, and M. Maiti, "1H NMR investigation of the interaction of berberine and sanguinarine with DNA," Indian Journal of Biochemistry and Biophysics, vol. 32, no. 2, pp. 74-77, 1995.

[40] D. S. Pilch, C. Yu, D. Makhey, et al., "Minor groove-directed and intercalative ligand-DNA interactions in the poisoning of human DNA topoisomerase I by protoberberine analogs," Biochemistry, vol. 36, no. 41, pp. 12542-12553, 1997.

[41] W.-H. Chen, C.-L. Chan, Z. Cai, G.-A. Luo, and Z.-J. Jiang, "Study on noncovalent complexes of cytotoxic protoberberine alkaloids with double-stranded DNA by using electrospray ionization mass spectrometry," Bioorganic \& Medicinal Chemistry Letters, vol. 14, no. 19, pp. 4955-4959, 2004.

[42] K. Bhadra, M. Maiti, and G. S. Kumar, "Thermodynamics of the binding of cytotoxic protoberberine molecule coralyne to deoxyribonucleic acids," Biochimica et Biophysica Acta, vol. 1780, no. 2, pp. 298-306, 2008.

[43] K. Bhadra, M. Maiti, and G. S. Kumar, "DNA-binding cytotoxic alkaloids: comparative study of the energetics of binding of berberine, palmatine, and coralyne," DNA and Cell Biology, vol. 27, no. 12, pp. 675-685, 2008.

[44] W. Y. Li, H. Lu, C. X. Xu, J. B. Zhang, and Z. H. Lu, "Spectroscopic and binding properties of berberine to DNA and its application to DNA detection," Spectroscopy Letters, vol. 31, no. 6, pp. 1287-1298, 1998.

[45] S. Mazzini, M. C. Bellucci, and R. Mondelli, "Mode of binding of the cytotoxic alkaloid berberine with the double helix oligonucleotide d(AAGAATTCTT) $)_{2}$," Bioorganic and Medicinal Chemistry, vol. 11, no. 4, pp. 505-514, 2003.

[46] J.-J. Zhu, J.-J. Zhang, G.-C. Zhao, and H.-Y. Chen, "Study of interaction of berberine with DNA in the presence of $\beta$ cyclodextrin," Spectroscopy Letters, vol. 31, no. 8, pp. 1705$1718,1998$.

[47] W.-H. Chen, Y. Qin, Z. Cai, C.-L. Chan, G.-A. Luo, and Z.H. Jiang, "Spectrometric studies of cytotoxic protoberberine alkaloids binding to double-stranded DNA," Bioorganic and Medicinal Chemistry, vol. 13, no. 5, pp. 1859-1866, 2005. 
[48] S. Das, G. S. Kumar, A. Ray, and M. Maiti, "Spectroscopic and thermodynamic studies on the binding of sanguinarine and berberine to triple and double helical DNA and RNA structures," Journal of Biomolecular Structure and Dynamics, vol. 20, no. 5, pp. 703-714, 2003.

[49] G. S. Kumar, S. Das, K. Bhadra, and M. Maiti, "Protonated forms of poly $[\mathrm{d}(\mathrm{G}-\mathrm{C})]$ and $\operatorname{poly}(\mathrm{dG}) \cdot \operatorname{poly}(\mathrm{dC})$ and their interaction with berberine," Bioorganic and Medicinal Chemistry, vol. 11, no. 23, pp. 4861-4870, 2003.

[50] J. Ren and J. B. Chaires, "Sequence and structural selectivity of nucleic acid binding ligands," Biochemistry, vol. 38, no. 49, pp. 16067-16075, 1999.

[51] M. Maiti, "DNA triple helical structures: their interaction with aristololactam- $\beta$-D-glucoside," in Perspectives in Structural Biology, M. Vijayan, N. Yathindra, and A. S. Kolaskar, Eds., pp. 583-592, Hyderabad University Press, Hyderabad, India, 1999.

[52] A. Ray, G. S. Kumar, S. Das, and M. Maiti, "Spectroscopic studies on the interaction of aristololactam-beta-D-glucoside with DNA and RNA double and triple helices: a comparative study," Biochemistry, vol. 38, no. 19, pp. 6239-6247, 1999.

[53] M. D. Keppler, S. Neidle, and K. R. Fox, "Stabilisation of TGand AG-containing antiparallel DNA triplexes by triplexbinding ligands," Nucleic Acids Research, vol. 29, no. 9, pp. 1935-1942, 2001.

[54] P. B. Dervan, "Molecular recognition of DNA by small molecules," Bioorganic and Medicinal Chemistry, vol. 9, no. 9, pp. 2215-2235, 2001.

[55] M. Polak and N. V. Hud, "Complete disproportionation of duplex poly $(\mathrm{dT}) \cdot \operatorname{poly}(\mathrm{dA})$ into triplex poly $(\mathrm{dT}) \cdot \operatorname{poly}(\mathrm{dA})$ .poly(dT) and poly(dA) by coralyne," Nucleic Acids Research, vol. 30, no. 4, pp. 983-992, 2002.

[56] K. Bhadra, M. Maiti, and G. S. Kumar, "Molecular recognition of DNA by small molecules: AT base pair specific intercalative binding of cytotoxic plant alkaloid palmatine," Biochimica et Biophysica Acta, vol. 1770, no. 7, pp. 1071-1080, 2007.

[57] A. Adhikari, M. Hossain, M. Maiti, and G. S. Kumar, "Energetics of the binding of phototoxic and cytotoxic plant alkaloid sanguinarine to DNA: isothermal titration calorimetric studies," Journal of Molecular Structure, vol. 889, no. 1-3, pp. 54-63, 2008.

[58] J. Suhnel, "Beyond nucleic acid base pairs: from triads to heptads," Biopolymers, vol. 61, no. 1, pp. 32-51, 2002.

[59] L. H. Hurley, R. T. Wheelhouse, D. Sun, et al., "Gquadruplexes as targets for drug design," Pharmacology and Therapeutics, vol. 85, no. 3, pp. 141-158, 2000.

[60] K. C. Gornall, S. Samosorn, J. Talib, J. B. Bremner, and J. L. Beck, "Selectivity of an indolyl berberine derivative for tetrameric G-quadruplex DNA," Rapid Communications in Mass Spectrometry, vol. 21, no. 11, pp. 1759-1766, 2007.

[61] D. Sen and W. Gilbert, "Formation of parallel four-stranded complexes by guanine-rich motifs in DNA and its implications for meiosis," Nature, vol. 334, no. 6180, pp. 364-366, 1988.

[62] E. H. Blackburn, "Structure and function of telomeres," Nature, vol. 350, no. 6319, pp. 569-573, 1991.

[63] E. M. Rezler, D. J. Bearss, and L. H. Hurley, "Telomere inhibition and telomere disruption as processes for drug targeting," Annual Review of Pharmacology and Toxicology, vol. 43, pp. 359-379, 2003.
[64] J. Karlseder, D. Broccoli, Y. Dai, S. Hardy, and T. de Lange, "p53- and ATM-dependent apoptosis induced by telomeres lacking TRF2," Science, vol. 283, no. 5406, pp. 1321-1325, 1999.

[65] E. Izbicka, R. T. Wheelhouse, E. Raymond, et al., "Effects of cationic porphyrins as G-quadruplex interactive agents in human tumor cells," Cancer Research, vol. 59, no. 3, pp. 639644, 1999.

[66] I. Naasani, H. Seimiya, T. Yamori, and T. Tsuruo, "FJ5002: a potent telomerase inhibitor identified by exploiting the disease-oriented screening program with COMPARE analysis," Cancer Research, vol. 59, no. 16, pp. 4004-4011, 1999.

[67] M. Franceschin, L. Rossetti, A. D’Ambrosio, et al., "Natural and synthetic G-quadruplex interactive berberine derivatives," Bioorganic \& Medicinal Chemistry Letters, vol. 16, no. 6, pp. 1707-1711, 2006.

[68] J. S. Lee, L. J. P. Latimer, and K. J. Hampel, "Coralyne binds tightly to both $\mathrm{T} \cdot \mathrm{A} \cdot \mathrm{T}$ - and $\mathrm{C} \cdot \mathrm{G} \cdot \mathrm{C}^{+}$-containing DNA triplexes," Biochemistry, vol. 32, no. 21, pp. 5591-5597, 1993.

[69] J. Kluza, B. Baldeyrou, P. Colson, et al., "Cytotoxicity and DNA binding properties of the plant alkaloid burasaine," European Journal of Pharmaceutical Sciences, vol. 20, no. 4-5, pp. 383-391, 2003.

[70] Y. Yu, C.-Y. Long, S.-Q. Sun, and J.-P. Liu, "Application of an alkaloid as a novel fluorescence probe in the determination of DNA," Analytical Letters, vol. 34, no. 15, pp. 2659-2669, 2001.

[71] A. Das, Photophysical and photochemical aspects of alkaloids and their interaction with nucleic acids, Ph.D. thesis, Jadavpur University, Kolkata, India, 1995.

[72] M. Hossain, Biophysical studies on the interaction of intercalating and groove binding molecules with deoxyribonucleic acids, Ph.D. thesis, Jadavpur University, Kolkata, India, 2009.

[73] K. Y. Zee-Cheng and C. C. Cheng, "Interaction between dna and coralyne acetosulfate, an antileukemic compound," Journal of Pharmaceutical Sciences, vol. 62, no. 9, pp. 15721573, 1973.

[74] W. D. Wilson, A. N. Gough, J. J. Doyle, and M. W. Davidson, "Coralyne. Intercalation with DNA as a possible mechanism of antileukemic action," Journal of Medicinal Chemistry, vol. 19, no. 10, pp. 1261-1263, 1976.

[75] K. Bhadra, M. Maiti, and G. S. Kumar, "Interaction of isoquinoline alkaloids with polymorphic DNA structures," Chemistry and Biodiversity, vol. 6, no. 9, pp. 1323-1342, 2009.

[76] R. Nandi, D. Debnath, and M. Maiti, "Interactions of berberine with poly(A) and tRNA," Biochimica et Biophysica Acta, vol. 1049, no. 3, pp. 339-342, 1990.

[77] P. Giri, M. Hossain, and G. S. Kumar, "RNA specific molecules: cytotoxic plant alkaloid palmatine binds strongly to poly(A)," Bioorganic \& Medicinal Chemistry Letters, vol. 16, no. 9, pp. 2364-2368, 2006.

[78] P. Giri and G. S. Kumar, "Specific binding and self-structure induction to poly(A) by the cytotoxic plant alkaloid sanguinarine," Biochimica et Biophysica Acta, vol. 1770, no. 9, pp. 1419-1426, 2007.

[79] P. Giri and G. S. Kumar, "Self-structure induction in single stranded poly(A) by small molecules: studies on DNA intercalators, partial intercalators and groove binding molecules," Archives of Biochemistry and Biophysics, vol. 474, no. 1, pp. 183-192, 2008.

[80] W. A. Creasey, "Biochemical effects of berberine," Biochemical Pharmacology, vol. 28, no. 7, pp. 1081-1084, 1979. 
[81] A. A. Moraru-Allen, S. Cassidy, J.-L. A. Alvarez, K. R. Fox, T. Brown, and A. N. Lane, "Coralyne has a preference for intercalation between TA.T triples in intramolecular DNA triple helices," Nucleic Acids Research, vol. 25, no. 10, pp. 1890-1896, 1997.

[82] S. S. Jain, M. Polak, and N. V. Hud, "Controlling nucleic acid secondary structure by intercalation: effects of DNA strand length on coralyne-driven duplex disproportionation," Nucleic Acids Research, vol. 31, no. 15, pp. 4608-4615, 2003.

[83] O. Persil, C. T. Santai, S. S. Jain, and N. V. Hud, "Assembly of an antiparallel homo-adenine DNA duplex by smallmolecule binding," Journal of the American Chemical Society, vol. 126, no. 28, pp. 8644-8645, 2004.

[84] R. Nandi and M. Maiti, "Binding of sanguinarine to deoxyribonucleic acids of differing base composition," Biochemical Pharmacology, vol. 34, no. 3, pp. 321-324, 1985.

[85] R. Nandi, K. Chaudhuri, and M. Maiti, "Effects of ionic strength and $\mathrm{pH}$ on the binding of sanguinarine to deoxyribonucleic acid," Photochemistry and Photobiology, vol. 42, no. 5, pp. 497-503, 1985.

[86] M. Maiti and R. Nandi, "Circular dichroism of sanguinarineDNA complexes: effect of base composition, $\mathrm{pH}$ and ionic strength," Journal of Biomolecular Structure and Dynamics, vol. 5, no. 1, pp. 159-175, 1987.

[87] A. Sen and M. Maiti, "Interaction of sanguinarine iminium and alkanolamine form with calf thymus DNA," Biochemical Pharmacology, vol. 48, no. 11, pp. 2097-2102, 1994.

[88] M. Maiti, S. Das, A. Sen, A. Das, G. S. Kumar, and R. Nandi, "Influence of DNA structures on the conversion of sanguinarine alkanolamine form to iminium form," Journal of Biomolecular Structure and Dynamics, vol. 20, no. 3, pp. 455-464, 2002.

[89] M. D. Faddejeva, T. N. Belyaeva, Yu. Rosanor, M. Sedova, and E. L. Sokolovskaya, "Studies on the complex formation with DNA and the effect on DNA hydrolysis, RNA synthesis and cellular membrane ATPase systems of some antitumor agants including alkaloids," Studia Biophysica, vol. 104, no. 1-3, pp. 267-269, 1984.

[90] N. P. Bajaj, M. J. McLean, M. J. Waring, and E. Smekal, "Sequence-selective, $\mathrm{pH}$-dependent binding to DNA of benzophenanthridine alkaloids," Journal of Molecular Recognition, vol. 3, no. 1, pp. 48-54, 1990.

[91] J. Urbanova, P. Lubal, I. Slaninova, E. Taborska, and P. Taborsky, "Fluorescence properties of selected benzo[c]phenantridine alkaloids and studies of their interaction with CT DNA," Analytical and Bioanalytical Chemistry, vol. 394, no. 4, pp. 997-1002, 2009.

[92] E. Smekal, N. Kubova, and V. Kleinwatcher, "Interaction of benzophenanthridine alkaloid sanguinarine with DNA," Studia Biophysica, vol. 101, pp. 125-132, 1984.

[93] L.-P. Bai, Z. Cai, Z.-Z. Zhao, K. Nakatani, and Z.-H. Jiang, "Site-specific binding of chelerythrine and sanguinarine to single pyrimidine bulges in hairpin DNA," Analytical and Bioanalytical Chemistry, vol. 392, no. 4, pp. 709-716, 2008.

[94] S. Das, G. S. Kumar, and M. Maiti, "Conversions of the lefthanded form and the protonated form of DNA back to the bound right-handed form by sanguinarine and ethidium: a comparative study," Biophysical Chemistry, vol. 76, no. 3, pp. 199-218, 1999.

[95] M. Maiti, "Molecular aspects on the interaction of sanguinarine with B-form, Z-form and HL-form DNA structures," Indian Journal of Biochemistry and Biophysics, vol. 38, no. 1-2, pp. 20-26, 2001.
[96] L. J. Latimer, N. Payton, G. Forsyth, and J. S. Lee, "The binding of analogues of coralyne and related heterocyclics to DNA triplexes," Biochemistry and Cell Biology, vol. 73, no. 12, pp. 11-18, 1995.

[97] L. P. Bai, M. Hagihara, Z. H. Jiang, and K. Nakatani, "Ligand binding to tandem $\mathrm{G}$ quadruplexes from human telomeric DNA," ChemBioChem, vol. 9, no. 16, pp. 2583-2587, 2008.

[98] P. Nelson, M. Kiriakidou, A. Sharma, E. Maniataki, and Z. Mourelatos, "The microRNA world: small is mighty," Trends in Biochemical Sciences, vol. 28, no. 10, pp. 534-540, 2003.

[99] C. C. Esau and B. P. Monia, "Therapeutic potential for microRNAs," Advanced Drug Delivery Reviews, vol. 59, no. 23, pp. 101-114, 2007.

[100] M. Takasugi, A. Guendouz, M. Chassignol, et al., "Sequencespecific photo-induced cross-linking of the two strands of double-helical DNA by a psoralen covalently linked to a triple helix-forming oligonucleotide," Proceedings of the National Academy of Sciences of the United States of America, vol. 88, no. 13 , pp. 5602-5606, 1991.

[101] M. Wickens, P. Anderson, and R. J. Jackson, "Life and death in the cytoplasm: messages from the $3^{\prime}$ end," Current Opinion in Genetics and Development, vol. 7, no. 2, pp. 220-232, 1997.

[102] K. Dower, N. Kuperwasser, H. Merrikh, and M. Rosbash, "A synthetic A tail rescues yeast nuclear accumulation of a ribozyme-terminated transcript," RNA, vol. 10, no. 12, pp. 1888-1899, 2004.

[103] F. W. Alt, A. L. M. Bothwell, M. Knapp, et al., "Synthesis of secreted and membrane-bound immunoglobulin Mu heavy chains is directed by mRNAs that differ at their $3^{\prime}$ ends," Cell, vol. 20, no. 2, pp. 293-301, 1980.

[104] M. A. McDevitt, R. P. Hart, W. W. Wong, and J. R. Nevins, "Sequences capable of restoring poly(A) site function define two distinct downstream elements," The EMBO Journal, vol. 5, no. 11, pp. 2907-2913, 1986.

[105] D. N. Holcomb and I. Tinoco Jr., "Conformation of polyriboadenylic acid: $\mathrm{pH}$ and temperature dependence," Biopolymers, vol. 3, no. 2, pp. 121-133, 1965.

[106] M. Leng and G. Felsenfeld, "A study of polyadenylic acid at neutral pH," Journal of Molecular Biology, vol. 15, no. 2, pp. 455-466, 1966.

[107] S. L. Topalian, S. Kaneko, M. I. Gonzales, G. L. Bond, Y. Ward, and J. L. Manley, "Identification and functional characterization of Neo-poly(A) polymerase, an RNA processing enzyme overexpressed in human tumors," Molecular and Cellular Biology, vol. 21, no. 16, pp. 5614-5623, 2001.

[108] S. L. Topalian, M. I. Gonzales, Y. Ward, X. Wang, and R.F. Wang, "Revelation of a cryptic major histocompatibility complex class II-restricted tumor epitope in a novel RNAprocessing enzyme," Cancer Research, vol. 62, no. 19, pp. 5505-5509, 2002.

[109] R. C. Yadav, G. S. Kumar, K. Bhadra, et al., "Berberine, a strong polyriboadenylic acid binding plant alkaloid: spectroscopic, viscometric, and thermodynamic study," Bioorganic and Medicinal Chemistry, vol. 13, no. 1, pp. 165-174, 2005.

[110] F. Xing, G. Song, J. Ren, J. B. Chaires, and X. Qu, "Molecular recognition of nucleic acids: coralyne binds strongly to poly(A)," FEBS Letters, vol. 579, no. 22, pp. 5035-5039, 2005.

[111] W. Saenger, Principles of Nucleic Acid Structure, Springer, New York, NY, USA, 1994.

[112] A. G. Petrovic and P. L. Polavarapu, "Structural transitions in polyriboadenylic acid induced by the changes in $\mathrm{pH}$ and temperature: vibrational circular dichroism study in solution and film states," The Journal of Physical Chemistry B, vol. 109, no. 49, pp. 23698-23705, 2005. 
[113] M. I. Zarudnaya and D. M. Hovorun, "Hypothetical doublehelical poly(A) formation in a cell and its possible biological significance," IUBMB Life, vol. 48, no. 6, pp. 581-584, 1999.

[114] P. Giri, M. Hossain, and G. S. Kumar, "Molecular aspects on the specific interaction of cytotoxic plant alkaloid palmatine to poly(A)," International Journal of Biological Macromolecules, vol. 39, no. 4-5, pp. 210-221, 2006.

[115] S. Szeto, C. M. N. Yow, and K. W. Fung, "Characterization of berberine on human cancer cells in culture," Turkish Journal of Medical Sciences, vol. 32, no. 5, pp. 363-368, 2002.

[116] P. Giri and G. S. Kumar, "Molecular recognition of poly(A) targeting by protoberberine alkaloids: in vitro biophysical studies and biological perspectives," Molecular BioSystems. In press.

[117] J. C. Wang, "DNA topoisomerases: why so many?" The Journal of Biological Chemistry, vol. 266, no. 11, pp. 66596662, 1991.

[118] J. M. Berger, S. J. Gamblin, S. C. Harrison, and J. C. Wang, "Structure and mechanism of DNA topoisomerase II," Nature, vol. 379, no. 6562, pp. 225-232, 1996.

[119] J. Roca and J. C. Wang, "DNA transport by a type II DNA topoisomerase: evidence in favor of a two-gate mechanism," Cell, vol. 77, no. 4, pp. 609-616, 1994.

[120] J. J. Champoux, "DNA topoisomerases: structure, function, and mechanism," Annual Review of Biochemistry, vol. 70, pp. 369-413, 2001.

[121] P. Pantaziz, B. Giovanella, and M. L. Rothenberg, The Camptothecins: From Discovery to the Patient, vol. 1, New York Academy of Sciences, New York, NY, USA, 1996.

[122] A. Y. Chen and L. F. Lin, "DNA topoisomerases: essential enzymes and lethal targets," Annual Review of Pharmacology and Toxicology, vol. 34, pp. 191-218, 1994.

[123] A. H. Corbett and N. Osheroff, "When good enzymes go bad: conversion of topoisomerase II to a cellular toxin by antineoplastic drugs," Chemical Research in Toxicology, vol. 6, no. 5, pp. 585-597, 1993.

[124] G. A. Eitzen, J. D. Aitchison, R. K. Szilard, M. Veenhuis, W. M. Nuttley, and R. A. Rachubinski, "The Yarrowia lipolytica gene PAY2 encodes a $42-\mathrm{kDa}$ peroxisomal integral membrane protein essential for matrix protein import and peroxisome enlargement but not for peroxisome membrane proliferation," The Journal of Biological Chemistry, vol. 270, no. 3, pp. 1429-1436, 1995.

[125] J. M. Covey, C. Jaxel, K. W. Kohn, and Y. Pommier, "Proteinlinked DNA strand breaks induced in mammalian cells by camptothecin, an inhibitor of topoisomerase I," Cancer Research, vol. 49, pp. 5016-5022, 1989.

[126] D. S. Pilch, Z. Xu, Q. Sun, et al., "Characterizing the DNA binding modes of a topoisomerasei-poisoning terbenzimidazole: evidence for both intercalative and minor groove binding properties," Drug Design and Discovery, vol. 13, no. 3-4, pp. 115-133, 1996.

[127] Y.-H. Hsiang, R. Hertzberg, S. Hecht, and L. F. Liu, “Camptothecin induces protein-linked DNA breaks via mammalian DNA topoisomerase I," The Journal of Biological Chemistry, vol. 260, no. 27, pp. 14873-14878, 1985.

[128] Y.-H. Hsiang, L. F. Liu, M. E. Wall, et al., "DNA topoisomerase I-mediated DNA cleavage and cytotoxicity of camptothecin analogues," Cancer Research, vol. 49, no. 16, pp. 4385-4389, 1989.

[129] A. Bodley, L. F. Liu, M. Israel, et al., "DNA topoisomerase II-mediated interaction of doxorubicin and daunorubicin congeners with DNA," Cancer Research, vol. 49, no. 21, pp. 5969-5978, 1989.
[130] T.-K. Li, E. Bathory, E. J. LaVoie, et al., "Human topoisomerase I poisoning by protoberberines: potential roles for both drug-DNA and drug-enzyme interactions," Biochemistry, vol. 39, no. 24, pp. 7107-7116, 2000.

[131] P. Krishnan and K. F. Bastow, "The 9-position in berberine analogs is an important determinant of DNA topoisomerase II inhibition," Anti-Cancer Drug Design, vol. 15, no. 4, pp. 255-264, 2000.

[132] D. Makhey, B. Gatto, C. Yu, A. Liu, L. F. Liu, and E. J. LaVoie, "Coralyne and related compounds as mammalian topoisomerase I and topoisomerase II poisons," Bioorganic and Medicinal Chemistry, vol. 4, no. 6, pp. 781-791, 1996.

[133] M. M. Sanders, A. A. Liu, T.-K. Li, et al., "Selective cytotoxicity of topoisomerase-directed protoberberines against glioblastoma cells," Biochemical Pharmacology, vol. 56, no. 9, pp. 1157-1166, 1998.

[134] L.-K. Wang, B. D. Rogers, and S. M. Hecht, "Inhibition of topoisomerase I function by coralyne and 5,6dihydrocoralyne," Chemical Research in Toxicology, vol. 9, no. 1, pp. 75-83, 1996.

[135] J. Holy, G. Lamont, and E. Perkins, "Disruption of nucleocytoplasmic trafficking of cylin DI and topoisomerase II by sanguinarine," BMC Cell Biology, vol. 7, article 13, 2006.

[136] D. L. Crowe, "Mechanisms of DNA damage and repair in cancer chemotherapy," Recent Research Developments in Cancer, vol. 4, pp. 65-72, 2002.

[137] H. Babich, H. L. Zuckerbraun, I. B. Barber, S. B. Babich, and E. Borenfreund, "Cytotoxicity of sanguinarine chloride to cultured human cells from oral tissue," Pharmacology and Toxicology, vol. 78, no. 6, pp. 397-403, 1996.

[138] D. S. Bhakuni and S. Jain, "Protoberberine alkaloids," in The Alkaloids, vol. 28, pp. 95-181, Academic Press, New York, NY, USA, 1986.

[139] M. Suffness and G. A. Cordel, "Antitumor alkaloids," in The Alkaloids, vol. 25, pp. 171-178, Academic Press, New York, NY, USA, 1985.

[140] T. Schmeller, B. Latz-Bruning, and M. Wink, "Biochemical activities of berberine, palmatine and sanguinarine mediating chemical defence against microorganisms and herbivores," Phytochemistry, vol. 44, no. 2, pp. 257-266, 1997.

[141] V. Simanek, "Benzophenanthridine alkaloids," in The Alkaloids, vol. 26, pp. 185-240, Academic Press, New York, NY, USA, 1985.

[142] C.-L. Kuo, C.-W. Chi, and T.-Y. Liu, "The anti-inflammatory potential of berberine in vitro and in vivo," Cancer Letters, vol. 203, no. 2, pp. 127-137, 2004.

[143] K. W. Bentley, " $\beta$-phenylethylamines and the isoquinoline alkaloids," Natural Product Reports, vol. 18, no. 2, pp. 148170, 2001.

[144] R. Nandi, M. Maiti, K. Chaudhuri, S. B. Mahato, and A. K. Bairagi, "Sensitivity of vibrios to sanguinarine," Experientia, vol. 39, no. 5, pp. 524-525, 1983.

[145] F. E. Koehn and G. T. Carter, "The evolving role of natural products in drug discovery," Nature Reviews Drug Discovery, vol. 4, no. 3, pp. 206-220, 2005.

[146] D. J. Newman and G. M. Cragg, "Natural products as sources of new drugs over the last 25 years," Journal of Natural Products, vol. 70, no. 3, pp. 461-477, 2007.

[147] K. V. Anis, N. V. Rajeshkumar, and R. Kuttan, "Inhibition of chemical carcinogenesis by berberine in rats and mice," Journal of Pharmacy and Pharmacology, vol. 53, no. 5, pp. 763-768, 2001. 
[148] C.-W. Chi, Y.-F. Chang, T.-W. Chao, et al., "Flowcytometric analysis of the effect of Berberine on the expression of glucocorticoid receptors in human hepatoma HepG2 cells," Life Sciences, vol. 54, no. 26, pp. 2099-2107, 1994.

[149] C. L. Kuo, C. C. Chou, and Y.-M. Yung, "Berberine complexes with DNA in the berberine-induced apoptosis in human leukemic HL-60 cells," Cancer Letters, vol. 93, no. 2, pp. 193200, 1995.

[150] H.-L. Lin, T.-Y. Liu, C.-W. Wu, and C.-W. Chi, "Berberine modulates expression of $\mathrm{mdrl}$ gene product and the responses of digestive track cancer cells to Paclitaxel," British Journal of Cancer, vol. 81, no. 3, pp. 416-422, 1999.

[151] E.-S. Kim, S.-E. Yoo, K. Y. Yi, et al., "Design, syntheses and biological evaluations of nonpeptidic caspase 3 inhibitors," Bulletin of the Korean Chemical Society, vol. 23, no. 7, pp. 1003-1010, 2002.

[152] S. Jantova, L. Cipak, M. Cernukova, and D. Kostalova, "Effect of berberine on proliferation, cell cycle and apoptosis in HeLa and L1210 cells," Journal of Pharmacy and Pharmacology, vol. 55, no. 8, pp. 1143-1149, 2003.

[153] S. Letasiova, S. Jantova, M. Hornathova, and B. Lakotos, "Toxicity and apoptosis induced by berberine-a potential anticancer drug," Biologia, vol. 60, supplement 17, pp. 97100, 2005.

[154] H. L. Wu, C. Y. Hsu, W. H. Liu, and B. Y. M. Yung, "Berberine-induced apoptosis of human leukemia HL-60 cells is associated with down-regulation of nucleophosmin/B23 and telomerase activity," International Journal of Cancer, vol. 81, no. 6, pp. 923-929, 1999.

[155] S. K. Mantena, S. D. Sharma, and S. K. Katiyar, "Berberine inhibits growth, induces G1 arrest and apoptosis in human epidermoid carcinoma A431 cells by regulating CdkiCdk-cyclin cascade, disruption of mitochondrial membrane potential and cleavage of caspase 3 and PARP," Carcinogenesis, vol. 27, no. 10, pp. 2018-2027, 2006.

[156] R. Zhang, D. V. Dougherty, and M. L. Rosenblum, "Laboratory studies of berberine used alone and in combination with 1,3-bis(2-chloroethyl)-1-nitrosourea to treat melignant brain tumors," Chinese Medical Journal, vol. 103, no. 8, pp. 658-665, 1990.

[157] N. Iizuka, K. Miyamoto, K. Okita, et al., "Inhibitory effect of Coptidis Rhizoma and berberine on the proliferation of human esophageal cancer cell lines," Cancer Letters, vol. 148, no. 1, pp. 19-25, 2000.

[158] T. L. Serafim, P. J. Oliveira, V. A. Sardao, E. Perkins, D. Parke, and J. Holy, "Different concentrations of berberine result in distinct cellular localization patterns and cell cycle effects in a melanoma cell line," Cancer Chemotherapy and Pharmacology, vol. 61, no. 6, pp. 1007-1018, 2008.

[159] I. Naasani, H. Seimiya, T. Yamori, and T. Tsuruo, "FJ5002: a potent telomerase inhibitor identified by exploiting the disease-oriented screening program with COMPARE analysis," Cancer Research, vol. 59, no. 16, pp. 4004-4011, 1999.

[160] M. Nagayama, A. Sato, H. Hayakawa, T. Urano, Y. Takada, and A. Takada, "Plasminogen activators and their inhibitors in non-small cell lung cancer: low content of type 2 plasminogen activator inhibitor associated with tumor dissemination," Cancer, vol. 73, no. 5, pp. 1398-1405, 1994.

[161] M. Volm, G. van Kaick, and J. Mattern, "Analysis of $c$-fos, $c$ jun, $c$-erbB1, c-erbB2 and $c$-myc in primary lung carcinomas and their lymph node metastases," Clinical and Experimental Metastasis, vol. 12, no. 4, pp. 329-334, 1994.
[162] N. Mitani, K. Murakami, T. Yamaura, T. Ikeda, and I. Saiki, "Inhibitory effect of berberine on the mediastinal lymph node metastasis produced by orthotopic implantation of Lewis lung carcinoma," Cancer Letters, vol. 165, no. 1, pp. 3542, 2001.

[163] S. Jantova, L. Cipak, and S. Letasiova, "Berberine induces apoptosis through a mitochondrial/caspase pathway in human promonocytic U937 cells," Toxicology in Vitro, vol. 21, no. 1, pp. 25-31, 2007.

[164] C.-C. Lin, S.-Y. Lin, J.-G. Chung, J.-P. Lin, G.-W. Chen, and S.-T. Kao, "Down-regulation of cyclin B1 and Up-regulation of Weel by berberine promotes entry of leukemia cells into the G2/M-phase of the cell cycle," Anticancer Research, vol. 26, no. 2, pp. 1097-1104, 2006.

[165] S. M. Meeran, S. Katiyar, and S. K. Katiyar, "Berberineinduced apoptosis in human prostate cancer cells is initiated by reactive oxygen species generation," Toxicology and Applied Pharmacology, vol. 229, no. 1, pp. 33-43, 2008.

[166] K. Hayashi, K. Minoda, Y. Nagaoka, T. Hayashi, and S. Uesato, "Antiviral activity of berberine and related compounds against human cytomegalovirus," Bioorganic \& Medicinal Chemistry Letters, vol. 17, no. 6, pp. 1562-1564, 2007.

[167] M. L. Sethi, "Enzyme inhibition VI: inhibition of reverse transcriptase activity by protoberberine alkaloids and structure-activity relationships," Journal of Pharmaceutical Sciences, vol. 72, no. 5, pp. 538-541, 1983.

[168] R. N. DuBois, A. Radhika, B. S. Reddy, and A. J. Entingh, "Increased cyclooxygenase-2 levels in carcinogen-induced rat colonic tumors," Gastroenterology, vol. 110, no. 4, pp. 12591262, 1996.

[169] W. E. Smalley and R. N. DuBois, "Colorectal cancer and nonsteroidal anti-inflammatory drugs," Advances in Pharmacology, vol. 39, pp. 1-20, 1997.

[170] K. Fukuda, Y. Hibiya, M. Mutoh, M. Koshiji, S. Akao, and H. Fujiwara, "Inhibition by berberine of cyclooxygenase-2 transcriptional activity in human colon cancer cells," Journal of Ethnopharmacology, vol. 66, no. 2, pp. 227-233, 1999.

[171] R. Chinery, R. D. Beauchamp, Y. Shyr, S. C. Kirkland, R. J. Coffey, and J. D. Morrow, "Antioxidants reduce cyclooxygenase-2 expression, prostaglandin production, and proliferation in colorectal cancer cells," Cancer Research, vol. 58, no. 11, pp. 2323-2327, 1998.

[172] T. Kosaka, A. Miyata, H. Ihara, et al., "Characterization of the human gene (PTGS2) encoding prostaglandin-endoperoxide synthase 2," European Journal of Biochemistry, vol. 221, no. 3, pp. 889-897, 1994.

[173] M. Tsujii and R. N. DuBois, "Alterations in cellular adhesion and apoptosis in epithelial cells overexpressing prostaglandin endoperoxide synthase 2," Cell, vol. 83, no. 3, pp. 493-501, 1995.

[174] X.-W. Niu, T. Zeng, A.-L. Qu, et al., "Effects of 7bromoethoxybenzene-tetrahydropalmatine on voltagedependent currents in guinea pig ventricular myocytes," Zhongguo Yao Li Xue Bao, vol. 17, no. 3, pp. 227-229, 1996.

[175] Y.-L. Chang, S. Usami, M.-T. Hsieh, and M. J. Jiang, "Effects of palmatine on isometric force and intracellular calcium levels of arterial smooth muscle," Life Sciences, vol. 64, no. 8, pp. 597-606, 1999.

[176] S. D. Phillips and R. N. Castle, "A review of the chemistry of the antitumor benzo $[c]$ phenanthridine alkaloids nitidine and fagaronine and of the related antitumor alkaloid coralyne," Journal of Heterocyclic Chemistry, vol. 18, no. 2, pp. 223-232, 1981. 
[177] R. S. Gupta, W. Murray, and R. Gupta, "Cross resistance pattern towards anticancer drugs of a human carcinoma multidrug-resistant cell line," British Journal of Cancer, vol. 58, no. 4, pp. 441-447, 1988.

[178] B. Gatto, M. M. Sanders, C. Yu, et al., "Identification of topoisomerase I as the cytotoxic target of the protoberberine alkaloid coralyne," Cancer Research, vol. 56, no. 12, pp. 27952800, 1996.

[179] V. M. Adhami, M. H. Aziz, S. R. Reagan-Shaw, M. Nihal, H. Mukhtar, and N. Ahmad, "Sanguinarine causes cell cycle blockade and apoptosis of human prostate carcinoma cells via modulation of cyclin kinase inhibitor-cyclin-cyclindependent kinase machinery," Molecular Cancer Therapeutics, vol. 3, no. 8, pp. 933-940, 2004.

[180] N. Ahmad, S. Gupta, M. M. Husain, K. M. Heiskanen, and H. Mukhtar, "Differential antiproliferative and apoptotic response of sanguinarine for cancer cells versus normal cells," Clinical Cancer Research, vol. 6, no. 4, pp. 1524-1528, 2000.

[181] S. J. Chmura, M. E. Dolan, A. Cha, H. J. Mauceri, D. W. Kufe, and R. R. Weichselbaum, "In vitro and in vivo activity of protein kinase $\mathrm{C}$ inhibitor chelerythrine chloride induces tumor cell toxicity and growth delay in vivo," Clinical Cancer Research, vol. 6, no. 2, pp. 737-742, 2000.

[182] H. Ishii, Y.-I. Ichikawa, E. Kawanabe, et al., "Studies on the chemical constituents of rutaceous plants. LX. Development of a versatile method for syntheses of the antitumor benzo $[c]$ phenanthridine alkaloids. (9). Efficient syntheses and antitumor activities of nitidine and related nonphenolic benzo[c]phenanthridine alkaloids," Chemical and Pharmaceutical Bulletin, vol. 33, no. 10, pp. 4139-4151, 1985.

[183] A. Cabrespine, J.-O. Bay, C. Barthomeuf, H. Curé, P. Chollet, and E. Debiton, "In vitro assessment of cytotoxic agent combinations for hormone-refractory prostate cancer treatment," Anti-Cancer Drugs, vol. 16, no. 4, pp. 417-422, 2005.

[184] G. L. Southard, R. T. Boulware, D. R. Walborn, W. J. Groznik, E. E. Thorne, and S. L. Yankell, "Sanguinarine, a new antiplaque agent: retention and plaque specificity," The Journal of the American Dental Association, vol. 108, no. 3, pp. 338-341, 1984.

[185] M. Maiti, R. Nandi, and K. Chaudhuri, "The effect of $\mathrm{pH}$ on the absorption and fluorescence spectra of sanguinarine," Journal of Photochemistry and Photobiology, vol. 38, no. 2, pp. 245-249, 1983.

[186] R. R. Jones, R. J. Harkrader, and G. L. Southard, "The effect of $\mathrm{pH}$ on sanguinarine iminium ion form," Journal of Natural Products, vol. 49, no. 6, pp. 1109-1111, 1986.

[187] M. M. Chaturvedi, A. Kumar, B. G. Darnay, G. B. N. Chainy, S. Agarwal, and B. B. Aggarwal, "Sanguinarine (pseudochelerythrine) is a potent inhibitor of NF- $\kappa \mathrm{B}$ activation, $\mathrm{I} \kappa \mathrm{B} \alpha$ phosphorylation, and degradation," The Journal of Biological Chemistry, vol. 272, no. 48, pp. 30129-30134, 1997.

[188] V. Kaminskyy, K.-W. Lin, Y. Filyak, and R. Stoika, "Differential effect of sanguinarine, chelerythrine and chelidonine on DNA damage and cell viability in primary mouse spleen cells and mouse leukemic cells," Cell Biology International, vol. 32, no. 2, pp. 271-277, 2008.

[189] M. H. Han, S. O. Kim, G. Y. Kim, et al., "Induction of apoptosis by sanguinarine in C6 rat glioblastoma cells is associated with the modulation of the Bcl-2 family and activation of caspases through downregulation of extracellular signalregulated kinase and Akt," Anti-Cancer Drugs, vol. 18, no. 8, pp. 913-921, 2007.
[190] I. Slaninova, E. Taborska, H. Bochorakova, and J. Slanina, "Interaction of benzo $[c]$ phenanthridine and protoberberine alkaloids with animal and yeast cells," Cell Biology and Toxicology, vol. 17, no. 1, pp. 51-63, 2001.

[191] A. R. Hussain, N. A. Al-Jomah, A. K. Siraj, et al., "Sanguinarine-dependent induction of apoptosis in primary effusion lymphoma cells," Cancer Research, vol. 67, no. 8, pp. 3888-3897, 2007.

[192] D. E. Larsson, H. Lövborg, L. Rickardson, R. Larsson, K. Öberg, and D. Granberg, "Identification and evaluation of potential anti-cancer drugs on human neuroendocrine tumor cell lines," Anticancer Research, vol. 26, no. 6, pp. 41254129, 2006.

[193] S. Kim, T.-J. Lee, J. Leem, K. S. Choi, J.-W. Park, and T. K. Kwon, "Sanguinarine-induced apoptosis: generation of ROS, down-regulation of Bcl-2, c-FLIP, and synergy with TRAIL," Journal of Cellular Biochemistry, vol. 104, no. 3, pp. 895-907, 2008.

[194] S. S. Matkar, L. A. Wrischnik, and U. Hellmann-Blumberg, "Sanguinarine causes DNA damage and p53-independent cell death in human colon cancer cell lines," ChemicoBiological Interactions, vol. 172, no. 1, pp. 63-71, 2008. 

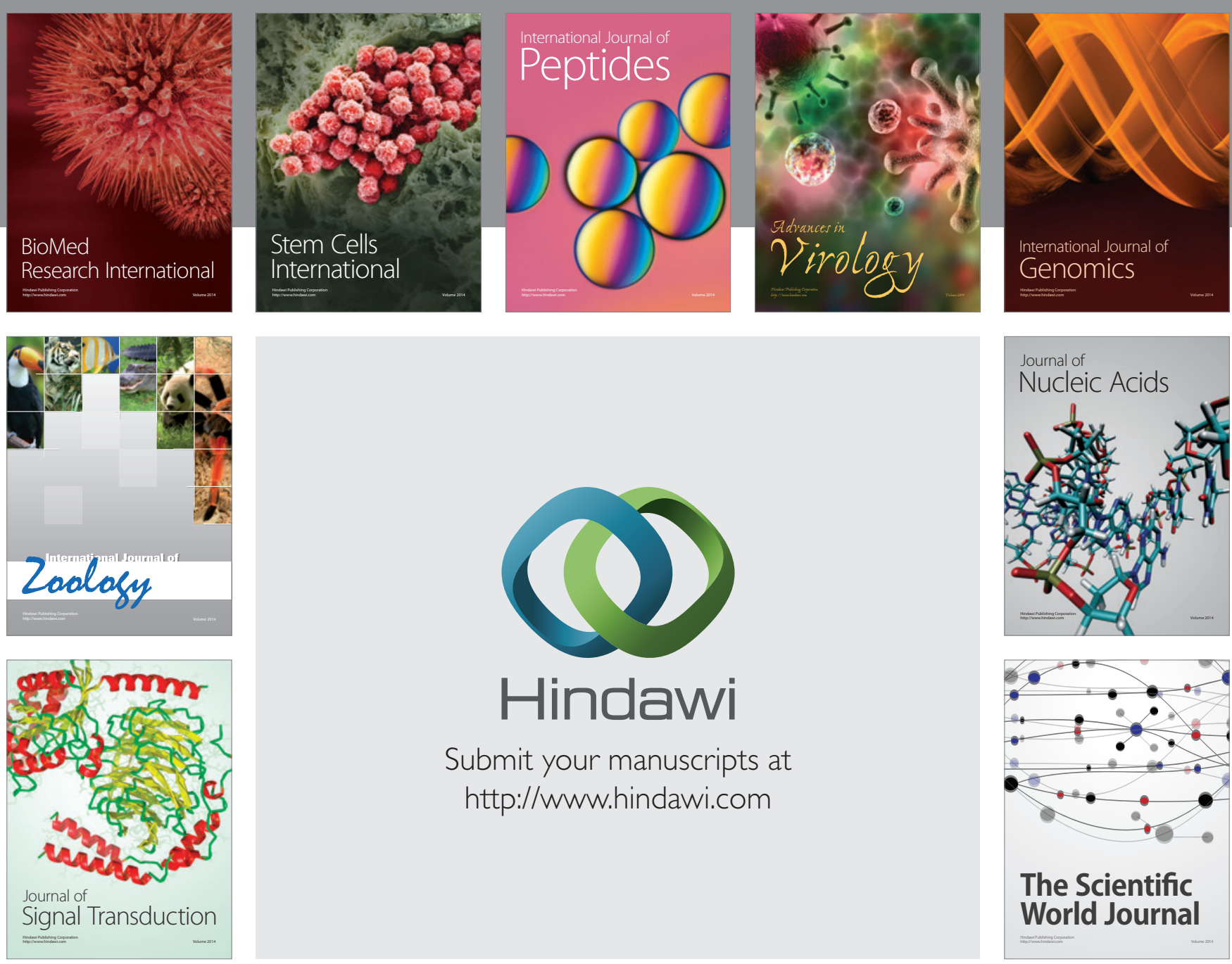

Submit your manuscripts at

http://www.hindawi.com
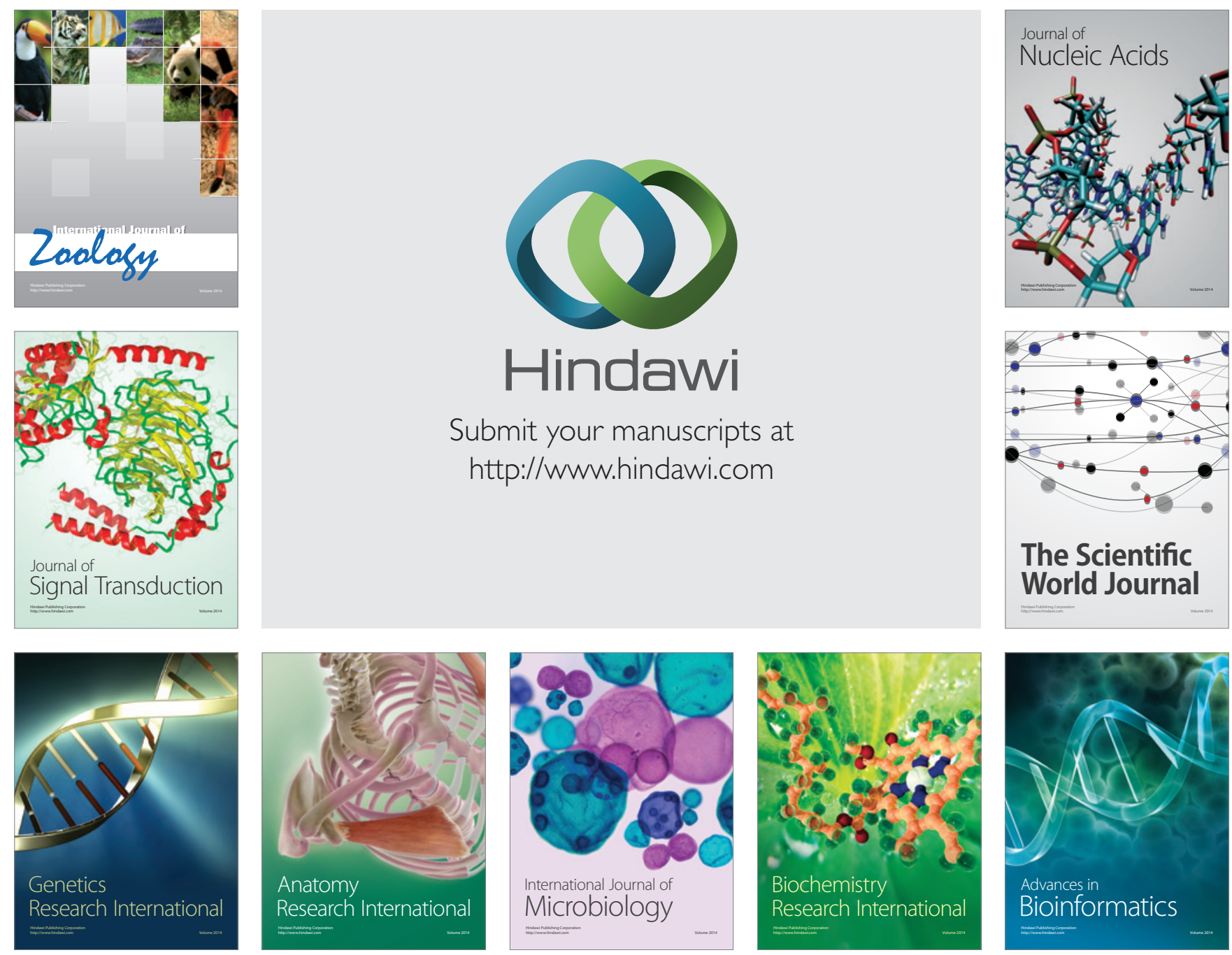

The Scientific World Journal
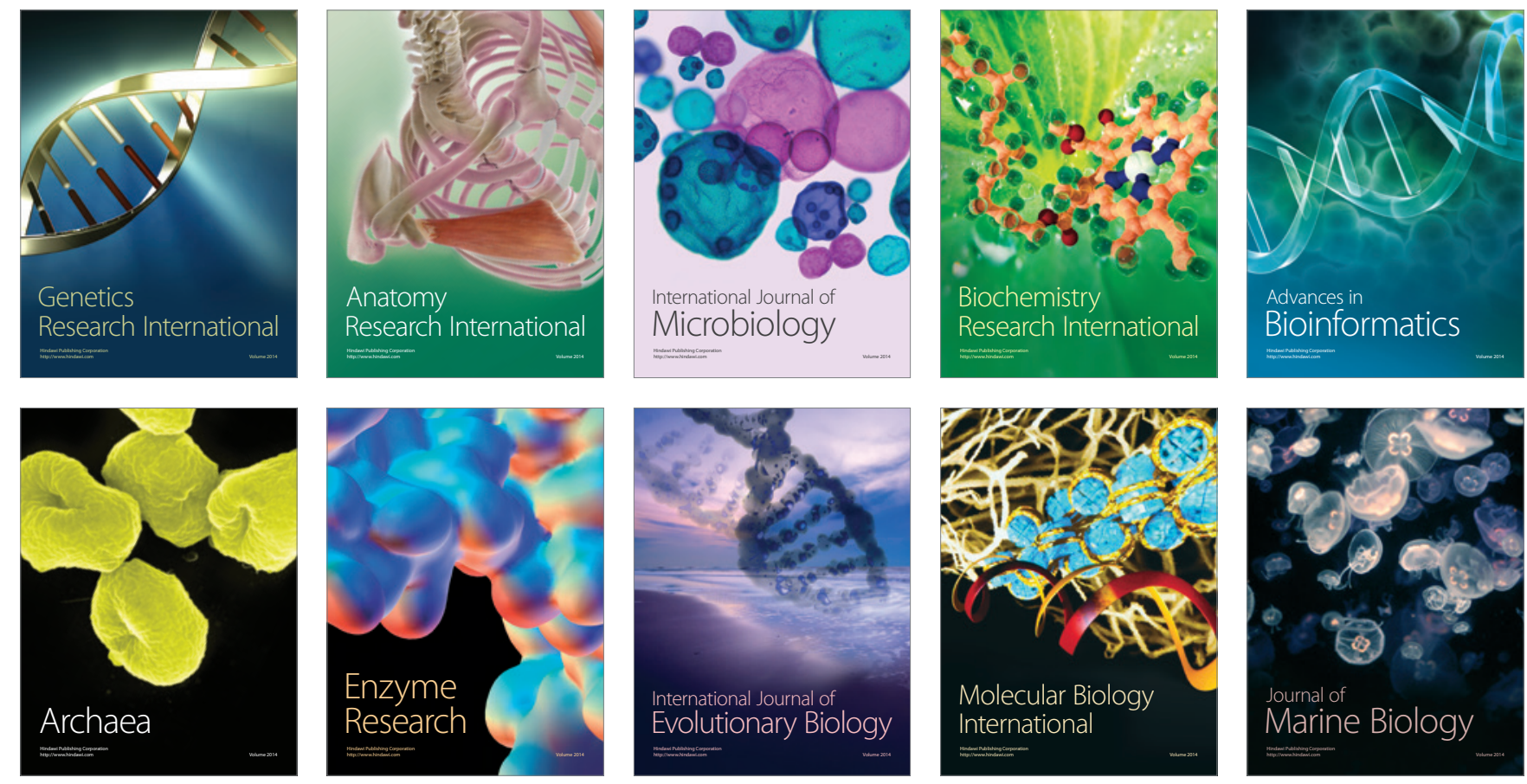